U. S. DEPARTMENT OF THE INTERIOR

U. S. GEOLOGICAL SURVEY

\title{
RELATION OF ARIAS INTENSITY TO MAGNITUDE AND \\ DISTANCE IN CALIFORNIA
}

\author{
by
}

Raymond C. Wilson ${ }^{1}$

OPEN-FILE REPORT 93-556

This report is preliminary and has not been reviewed for conformity with U.S. Geological Survey editorial standards or with the North American Stratigraphic Code. Any use of trade, product, or firm names is for descriptive purposes only and does not imply endorsement by the U. S.. Government.

${ }^{1}$ Menlo Park, California 94025

September 1993 
Abstract.......................................................................1

Introduction...........................................................

Definition of Arias Intensity ..............................................3

Relating Intensity to the Seismic Source ...............................4

Arias Intensity and the Seismic Source Parameters..............4

Arias Intensity as a Function of Moment Magnitude..............6

Empirical Tests of the Theoretical $\mathrm{M} / \mathrm{R} / \mathrm{I}_{\mathrm{a}}$ Model.......................6

Arias Intensity as a Function of Distance...........................8

Arias Intensity as a Function of Magnitude........................ 12

Analysis of Residuals from a Combined Data Set................... 14

A Possible Simplification........................................... 18

Summary of Empirical Analyses.................................... 18

Modifications of the $M / R / I_{a}$ Relation for Special Conditions ....... 20

Site-Response Effects................................................ 20

Source Directivity ................................................. 2

Relations Between Site Effects, Directivity, and Stochastic

Variations..........................................................24

Predicting Earthquake-Induced Landslides ..........................24

Correlation of Arias Intensity with the Modified Mercalli Scale... 25

Re-evaluation of Arias's MMU/log( $\left.I_{h}\right)$ Regression................34

The 1979 Imperial Valley Event; an Anomaly?.................... 34

The Ih/MMI Relation, Still Ambiguous .......................... 35

Summary and Conclusions........................................... 36

Acknowledgments .................................................. 37

References Cited ................................................. 38

TABLES:

1. Strong-Motion Data Base..............................................

2. Arias Intensity and Modified Mercalli Intensity................28

FIGURES:

Figure 1. Arias Intensity versus source distance for 1971 San

Fernando earthquake.....................................9

2. Arias Intensity versus source distance for 1979

Imperial Valley earthquake........................... 10

3. Arias Intensity versus source distance for 1987

Whittier Narrows earthquake........................... 11

4. Plot of $A_{0}$ values versus moment magnitude for ten

California earthquakes.................................. 13

5. Residuals versus source distance for 210 strongmotion records.......................................... 15

6. Residuals versus moment magnitude for 210 strongmotion records............................................. 16 
Figure 7. Probability plot of residuals for 210 strong-motion records (from $A_{0}$ values)............................... 17

8. Probability plot of residuals for $\mathbf{2 1 0}$ strong-motion records (from equation 11)............................... 19

9. Directivity effects on Arias Intensity from 1980 Livermore earthquakes................................... 2

10. Earthquake-Induced landslides: Comparison of historic data with $\mathrm{M} / \mathrm{R} / \mathrm{Th}$ relation.

11. Plot of $\log \left(I_{h}\right)$ versus MMI values for 84 records from the 1987 Whittier Narrows earthquake.

12. Plot of $\log \left(I_{h}\right)$ versus $M M I$ values for 185 records from five well-recorded California earthquakes....... 31

13. Plot of $\log \left(I_{h}\right)$ versus MMI values for 22 records from the 1979 Imperial Valley earthquake. ............ 32

14. Probability plots of $\log \left(I_{h}\right)$ values versus $M M I$ grades V, VI, and VII. 


\section{ABSTRACT}

Arias intensity, proportional to the square of the ground acceleration integrated over time, provides a quantitative, instrumental measure of the severity of seismic shaking. A theoretical magnitude-distance relationship for Arias intensity, derived from the Brune seismic source model and the Hanks-McGuire model of high-frequency seismic ground motion, indicates an inverse-square relationship with source distance $(R)$ and a log-linear relation to moment magnitude (M).

This relationship was empirically verified with strong-motion data from several well recorded California earthquakes. The residuals are normally distributed and independent of both magnitude and distance, but have a standard deviation of 0.365 , indicating significant statistical variation in the strong-motion data set. Anelastic absorption has little effect for $R<150 \mathrm{~km}$. The static stress drop appears to be well-constrained about a value of 100 bars. Significant corrections may be necessary, however, for site-response effects in thick deposits of low-velocity material, and for events where asymmetrical source propagation may lead to azimuthal variations in seismic shaking.

Application of the magnitude-distance relation for Arias intensity is illustrated by using it, in combination with historical data on landslides in earthquakes, to predict limiting distances for seismically triggered landslides. Finally, a statistically significant linear correlation was found between Arias intensity and the Modified Mercalli scale, but questions remain about what may be, in fact, a more complex relationship.

\section{INTRODUCTION:}

Varied procedures have been developed for predicting some measure of the severity of seismic shaking as a function of the size of the seismic event and the distance from the source of the event to the site in question. Generally, these prediction methods are based on empirical analyses of existing data on the distribution of seismic energy, either in the form of instrumental measurements or isoseismal maps based on anecdotal evidence of perceptual effects and observations of structural damage. While the instrumental data has obvious advantages, it is often unavailable or sketchy, at best, so that isoseismal maps and intensity surveys still form the bulk of data available for prediction of ground motions in future events.

Peak acceleration is still the most popular instrumental measure of the severity of seismic shaking. The magnitude/distance/peak-acceleration relations developed by Schnabel and Seed (1973) and Joyner and Boore (1981) are used routinely for evaluating earthquake shaking hazards. However, as a number of authors (e.g. Housner, 1965; Ambraseys, 1974; Evernden, 1975; Evernden and others, 1981) have pointed out, peak acceleration alone does not completely characterize the severity of seismic shaking. For example, while peak acceleration is strongly influenced by high frequency 
components, lower frequency components may cause much of the structural damage, especially in multi-story buildings where resonance effects may occur. Further, the duration of shaking is also an important, though often neglected, parameter in describing seismic shaking. The intense, but relatively brief, shaking from the 1971 San Fernando earthquake, for example, left several critical structures very near failure, and a slightly longer duration could have caused greatly increased damage and loss of life (Housner, 1971).

The non-instrumental seismic intensity scales were developed from post-earthquake observations of structural damage and geologic effects. The Modified Mercalli Intensity (MMI) scale is usually used in this country (Wood and Neumann, 1931; modified by Richter, 1958), although some studies have used the Rossi-Forel scale (Evernden and others, 1981) and the 1906 San Francisco scale (Borcherdt and others, 1975). These scales implicitly reflect the effects of duration and other factors not reflected in the peak acceleration. However, the non-instrumental scales are nonparametric classification systems that express intensities only as integers, with no reliable, meaningful interpolations between integer values. Therefore, it is very difficult to translate predicted intensity levels based on these non-instrumental scales into practical design or code requirements.

A number of attempts have been made to correlate instrumental parameters with non-instrumental intensity scales. As discussed in a later section, the most popular combination seems to be peak acceleration with Modified Mercalli Intensity, beginning with Gutenberg and Richter, (1942). However, as Ambraseys (1974), Trifunac and Brady (1975), and many others have pointed out, such correlations look very attractive when made with relatively small data sets, but contain so much statistical variation in large data sets as to be of highly questionable utility.

This paper first reviews the concepts on which Arias (1970) developed his instrumental intensity scale. Next, a theoretical model for Arias intensity as a function of stress drop, source radius, and source distance, is developed from the seismic source model of Brune $(1970,1971)$ and the Hanks and McGuire (1981) model of high-frequency seismic ground acceleration as "band-limited white noise." This source parameter model is then converted into a theoretical relationship between Arias intensity, the moment magnitude, and the source distance. These theoretical relationships are then tested empirically, using strong-motion data from a number of California earthquakes. Modifications to the magnitudedistance relation are described to deal with site-response amplification and source-directivity effects. Application of the magnitude-distance relation for Arias intensity is illustrated by discussing its use for predicting limiting distances for seismically triggered landslides. Finally, a new attempt to correlate Arias intensity with the Modified Mercalli scale is described, along with possible complications. 


\section{DEFINITION OF ARIAS INTENSITY}

In deriving the intensity parameter identified with his name, Arturo Arias noted that,

"the ultimate purpose of (an) intensity scale is to give an indication of the potential damage that an earthquake can produce in the locality at which the intensity is being ascertained, independently of whether in that locality there are or there are no structures, and independently of the quality and nature of the structures that might exist." (Arias, 1970, p. 451).

Arias's principal assumption (p. 452) is that,

"the amount of damage experienced by a structure is proportional to the energy dissipated by the structure per unit weight during the overall duration of the motion induced on it by the earthquake."

In order to calculate the energy dissipated during shaking by a manmade structure, Arias idealized the structure as a damped, linear oscillator. He then hypothesized a population of many oscillators with resonant frequencies ranging from zero to infinity, all constrained to move in the same direction, and all with small damping ratios $(<0.1)$. Arias then stated (p. 453), "we shall define the intensity, I, of the earthquake...as the sum of the energies dissipated (per unit weight) by all the structures belonging to the population." He further noted that, "According to this definition, intensity has the dimensions of a velocity." After a lengthy analysis, Arias (1970, p. 455) derives the following relationship:

$$
I_{x x}=\frac{\pi}{2 g} \int_{0}^{t_{d}}\left(a_{x}(t)\right)^{2} d t
$$

where: $I_{x x}=x$-component of the intensity; $a_{x}(t)=x$-component of the ground acceleration, at time, $t ; t_{d}=$ total duration of the earthquake; and, $g$ $=$ acceleration due to gravity.

Arias intended that the above definition apply only to a single component of ground acceleration; the total intensity should be represented as the sum of the two horizontal components of ground motion, $\mathrm{I}_{h}=\mathrm{I}_{\mathrm{xx}}+$ $I_{y y}$. However, subsequent authors usually treat only the stronger horizontal component, $I_{a}$, as representing the severity of seismic shaking at that site (Dobry and others, 1978, Vanmarcke and Lai, 1980). Both usages are followed in this paper, distinguished by the subscript. 


\section{RELATING INTENSITY TO THE SEISMIC SOURCE}

\section{Arias Intensity and the Seismic Source Parameters:}

A promising approach to understanding the relationship between strong-motion parameters and the seismic source spectrum was proposed by Hanks (1979) and developed into a relationship between the source parameters and the root-mean-square (rms) acceleration by Hanks and McGuire (1981). Hanks and McGuire make use of Parseval's theorem, which states (e.g., Bracewell, 1965, p. 112), "the integral of the squared modulus of a function is equal to the integral of the squared modulus of its spectrum." Thus,

$$
\int_{-\infty}^{+\infty}(a(t))^{2} d t=\frac{1}{2 \pi} \int_{-\infty}^{+\infty}(a(\omega))^{2} d \omega
$$

where $\mathrm{a}(\mathrm{t})=$ ground acceleration (time domain), $\mathbf{a}(\omega)=$ acceleration spectral level (frequency domain), and $\omega=$ circular frequency $=2 \pi f$.

The integral over the infinite time domain may be approximated by integrating over the time interval, $t=0$ to $T_{d}(=$ inverse of the corner frequency, approximately the duration of strong shaking). According to the definition in eq. (1), the value of this integral is equal to $I_{a}(2 g / \pi)$.

The spectral integral may be evaluated using Hanks and McGuire's (1981) model of the high-frequency portion of the source spectrum as "bandlimited, finite duration white noise in ground acceleration" such that the level of the acceleration spectrum is approximately constant between a lower bound formed by the corner frequency, $f_{0}$, related to the source dimension, and an upper bounding frequency, $f_{\max }$. (This constant spectral acceleration also exists over the symmetrical negative frequency interval, $-\omega_{0}$ to $-\omega_{\max }$.) Following Hanks (1979), the value of the constant spectral acceleration is assumed to be $\mathbf{a}(\omega)=\Omega_{0} \omega_{0}{ }^{2}$, where $\Omega_{0}$ is the longperiod limit of the shear displacement spectrum, and $\omega_{0}=2 \pi f_{0}$. The upper frequency, $f_{\max }$, denotes the high-frequency band limitation of the radiated field of earthquakes (Hanks, 1982), and is assumed to have a constant value, $\sim 15 \mathrm{~Hz}$, for California events (Hanks and Boore, 1984). Thus, the spectral integral in eq. (2) may be approximated as,

$$
\int_{-\infty}^{+\infty}(\mathbf{a}(\omega))^{2} d \omega=2 \int_{\omega_{0}}^{\omega_{\max }}(\mathbf{a}(\omega))^{2} d \omega=2\left(\Omega_{0}^{2} \omega_{0}^{4}\right)\left(\omega_{\max }-\omega_{0}\right)
$$


By replacing the time-domain and frequency-domain integrals in eq. (2) with their approximate equivalents, and combining constants, the Arias intensity may now be expressed in terms of the source spectral parameters,

$$
I_{a}=\frac{\pi}{g}\left(\Omega_{0}^{2} \omega_{0}^{4}\right)\left(f_{\max }-f_{0}\right) .
$$

This relation may be carried further if we now assume a circular seismic source as described by the Brune $(1970,1971)$ model, so that, $\omega_{0}=$ $2.34 \beta / r_{0}$, where $\beta$ is the shear wave velocity and $r_{0}$ is the radius of seismic source, and the stress drop, $\Delta \sigma=106 \rho R \Omega_{0}{ }^{2} \omega_{0}^{3}$ (Hanks, 1979), where $\rho=$ bulk density and $R=$ distance from the seismic source. Combining and simplifying, we find,

$$
\mathbf{a}(\omega)=\Omega_{0} \omega_{0}^{2}=\frac{\Delta \sigma_{0}}{\rho \beta R},
$$

where $\Delta \sigma$ is stress drop and $r_{0}$ is source radius. Hanks and McGuire (1981, p. 2074) determined that radiation pattern effects and free-surface amplification, both neglected in the Brune model, could be combined into a correction factor equal to 0.85 in the value of the rms acceleration. Substituting eq. (5) into eq. (4), and adding the correction factor, we find that

$$
I_{a}=(0.85)^{2} \frac{\pi}{g} \frac{\Delta \sigma^{2}}{\rho^{2} \beta^{2}} \frac{r_{o}^{2}}{R^{2}}\left(f_{\max }-f_{o}\right)
$$

Anelastic attenuation, also neglected in the Brune model, is effectively nullified by the assumption of a constant value of $f_{\max }$ in the HanksMcGuire model. Empirical studies, discussed below, suggest that the effect of anelastic attenuation is negligible for moderate distances, $R<150 \mathrm{~km}$. Source directivity effects are discussed in a following section.

For convenience, equation (6) may be rewritten in logarithmic form (neglecting $f_{0}$ because $f_{\max } \gg f_{0}$ for $\underline{M}>4.5$ ) as,

where,

$$
\log \left(I_{a}\right)=2 \log (\Delta \sigma)+2 \log \left(r_{0}\right)-2 \log (R)+K_{0}
$$

$$
\mathrm{K}_{0}=\left((0.85)^{2} \frac{\pi}{\mathrm{g}} \frac{\mathrm{f}_{\max }}{\rho^{2} \beta^{2}}\right.
$$

For $I_{a}$ in $\mathrm{m} / \mathrm{s}, \Delta \sigma$ in bars, $r_{0}$ and $R$ in $\mathrm{km}$, and values of $\rho=2.7 \mathrm{~g} / \mathrm{cm}^{3}, \beta=$ $2.5 \mathrm{~km} / \mathrm{s}$, and $\mathrm{f}_{\max }=15 \mathrm{~Hz} ; \mathrm{K}_{0}=-3.12$. 
Arias Intensity as a Function of Moment Magnitude:

Using the Brune $(1970,1971)$ model, and accounting for differences in units $\left(M_{0}\right.$ in dyne-cm, $\Delta \sigma$ in bars, and $r_{0}$ in $\mathrm{km}$.), the seismic moment, $M_{0}$, may be expressed in terms of the stress drop and the source radius as,

$$
\log \left(\mathrm{M}_{0}\right)=\log (\Delta \sigma)+3 \log \left(\mathrm{r}_{0}\right)+21.36 .
$$

The moment-magnitude, $\mathbf{M}$, is defined (Hanks and Kanamori, 1979) as,

Thus,

$$
M=2 / 3 \log \left(M_{0}\right)-10.7
$$

$$
\mathbf{M}=2 / 3 \log (\Delta \sigma)+2 \log \left(r_{0}\right)+3.54
$$

Combining this relation with eq. (7) yields:

$$
\log \left(I_{a}\right)=4 / 3 \log (\Delta \sigma)+M-2 \log (R)-6.66 .
$$

If we neglect anelastic attenuation (discussed in the following section) and assume an average value of stress drop of approximately 100 bars (Hanks and McGuire, 1981; Boore, 1983), so that $\log (\Delta \sigma)=2.00$; then,

$$
\log \left(I_{a}\right)=\mathbf{M}-2 \log (R)-3.99 \text {. }
$$

Thus, a linear relationship should exist between the moment magnitude and the logarithm of the Arias intensity. This relationship and those on which it is based are subjected to various empirical tests in the following section.

\section{EMPIRICAL TESTS OF THE THEORETICAL M/R/ $\mathrm{a}_{\mathrm{a}}$ MODEL}

In this section, we examine how well the theoretical magnitudedistance relation for Arias intensity (equation 11) predicts the values of Arias intensity observed in actual earthquakes. This first-order model may have neglected or oversimplified complexities that could significantly influence the distribution of seismic energy, such as significant anelastic absorption or large variations in stress drop. We must also estimate the magnitude of random variations that may cause the observed values of Arias intensity to deviate from those predicted by the theoretical model.

In order to investigate these questions, a data base of Arias intensity, moment magnitude, and source distance was selected for ten California earthquakes (table 1 ). These events were all multiply recorded (at least 5 records) and four were well-recorded ( $>20$ records). This data forms the basis for empirical analyses of the following: (a) the attenuation of Arias intensity with increasing source distance; (b) the relationship between 


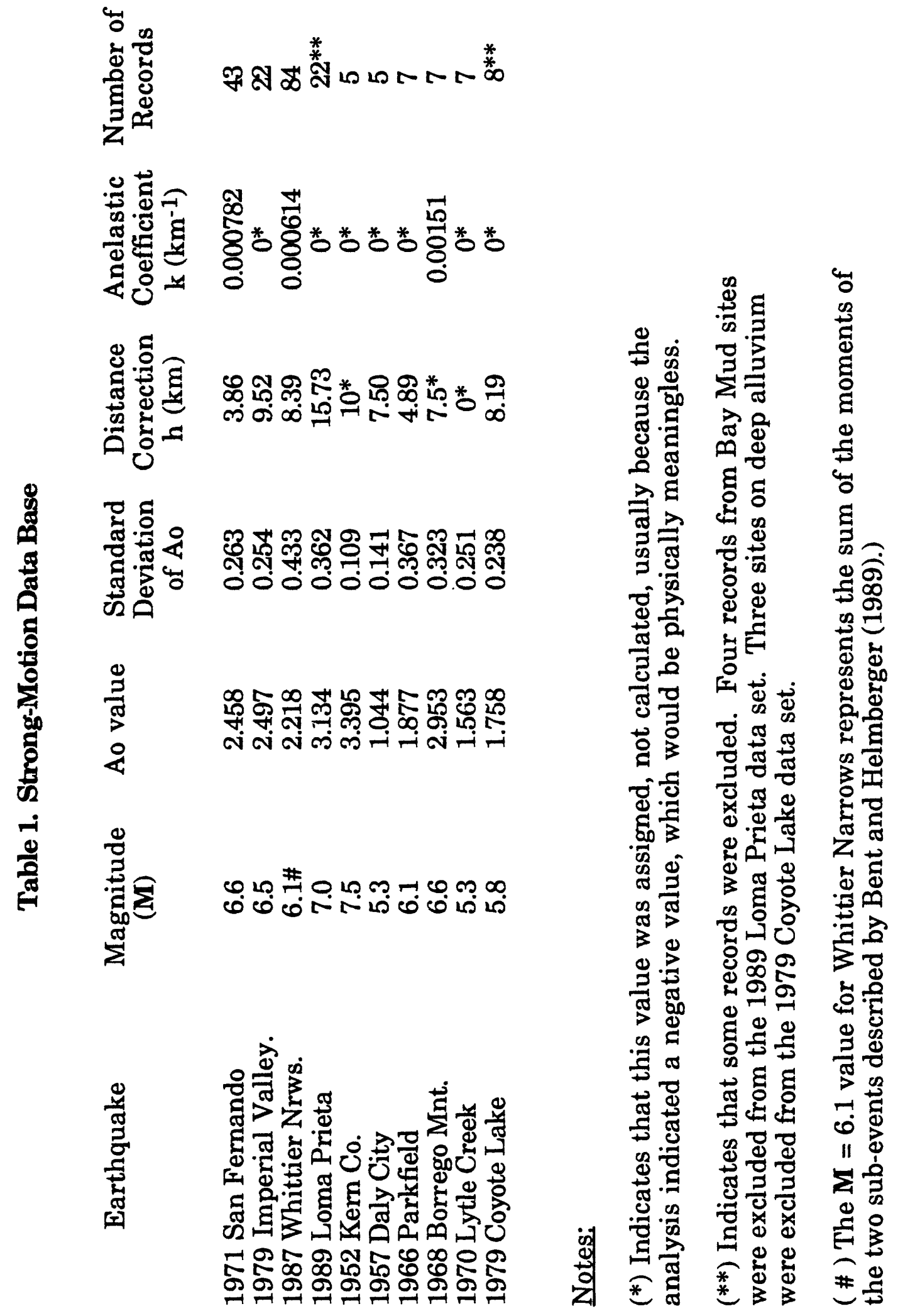


Arias intensity and moment magnitude; and, (c) the distribution of residuals resulting from subtracting predicted Arias intensity values from those actually observed.

\section{Arias Intensity as a Function of Distance:}

The attenuation of seismic energy over distance actually involves two distinct physical mechanisms--geometric spreading and anelastic absorption. Geometric spreading describes the divergence of seismic energy as it propagates from a central source region and may be modeled as an inverse-square relationship between seismic energy and the source distance, based on the conservation of energy. Anelastic absorption results from energy losses due to various dissipation mechanisms arising from the departure of earth materials from idealized elastic behavior and may be modeled as an exponential decay of seismic energy with source distance.

While geometric spreading should behave the same way in any part of the world, anelastic absorption might vary widely from region to region because of differences in material properties. This distinction has some relevance to discussion in the literature about differences in isoseismal areas, from events of similar magnitude, between the Pacific coast and the mid-continent, noted by several authors (e.g., Nuttli, 1973, Evernden, 1975). More recently, Hanks and Johnston (1992) have argued that such differences are much smaller than previously believed. Evaluation of the relative importance of anelastic absorption in seismic attenuation in California may shed some light on this issue.

In order to analyze the attenuation of Arias intensity with source distance, plots were made for three well-recorded earthquakes in California: 1971 San Fernando, M 6.6 (figure 1), 1979 Imperial Valley, M 6.5 (figure 2), and 1987 Whittier Narrows, M 6.1 (figure 3). These plots depict $\log \left(I_{h}\right)$ values versus $\log (D)$, where $D=$ minimum horizontal distance between the recording site and a vertical projection of the closest point on the source plane. For each attenuation plot, a line was fit to the data using the form:

$$
\log \left(I_{h}\right)=A_{0}-2 \log (R)-k R
$$

where $A_{0}$ is a proportionality constant related to the energy release from the seismic source, and $\mathbf{k}$ is the coefficient of anelastic absorption. Following Joyner and Boore (1981, p. 2013), the source distance, $R$, is calculated by combining the minimum horizontal distance from the recording site to the surface projection of the seismic source zone, $D$, with another term, $h$, in order to "allow for the fact that the source of the peak motion values may not be the closest point on the rupture," so that, $R=$ $\sqrt{\mathrm{D}^{2}+\mathrm{h}^{2}}$. 

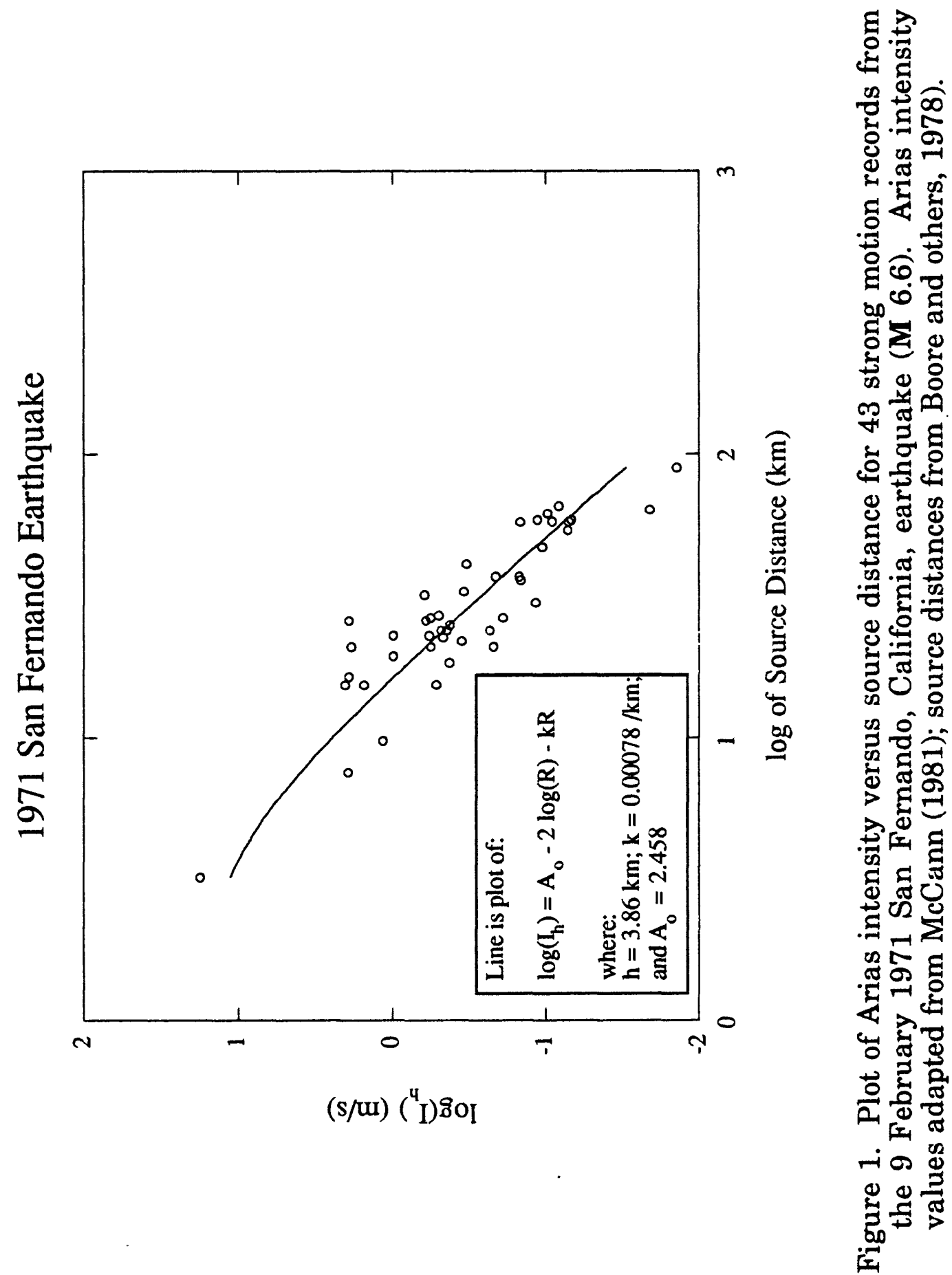

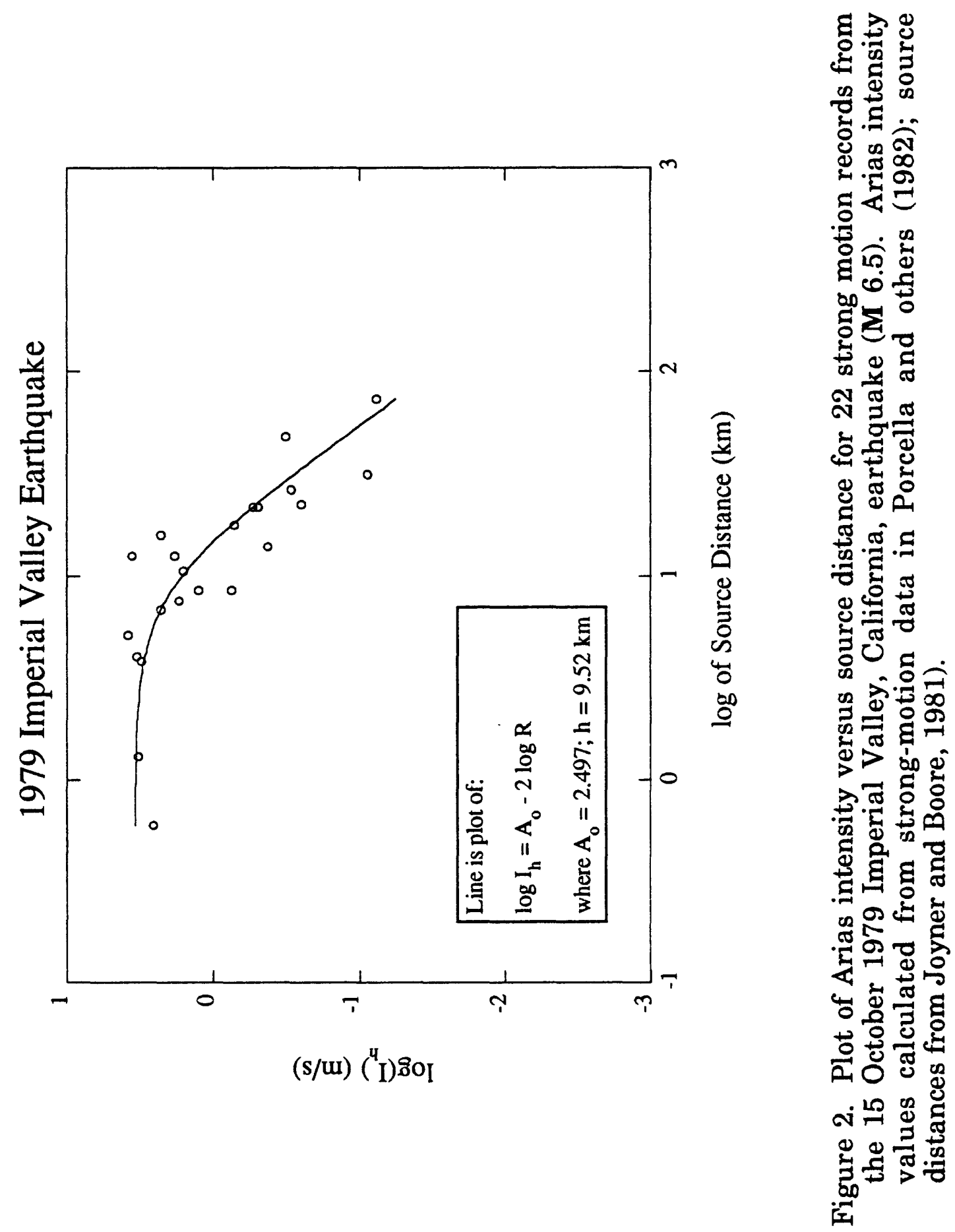

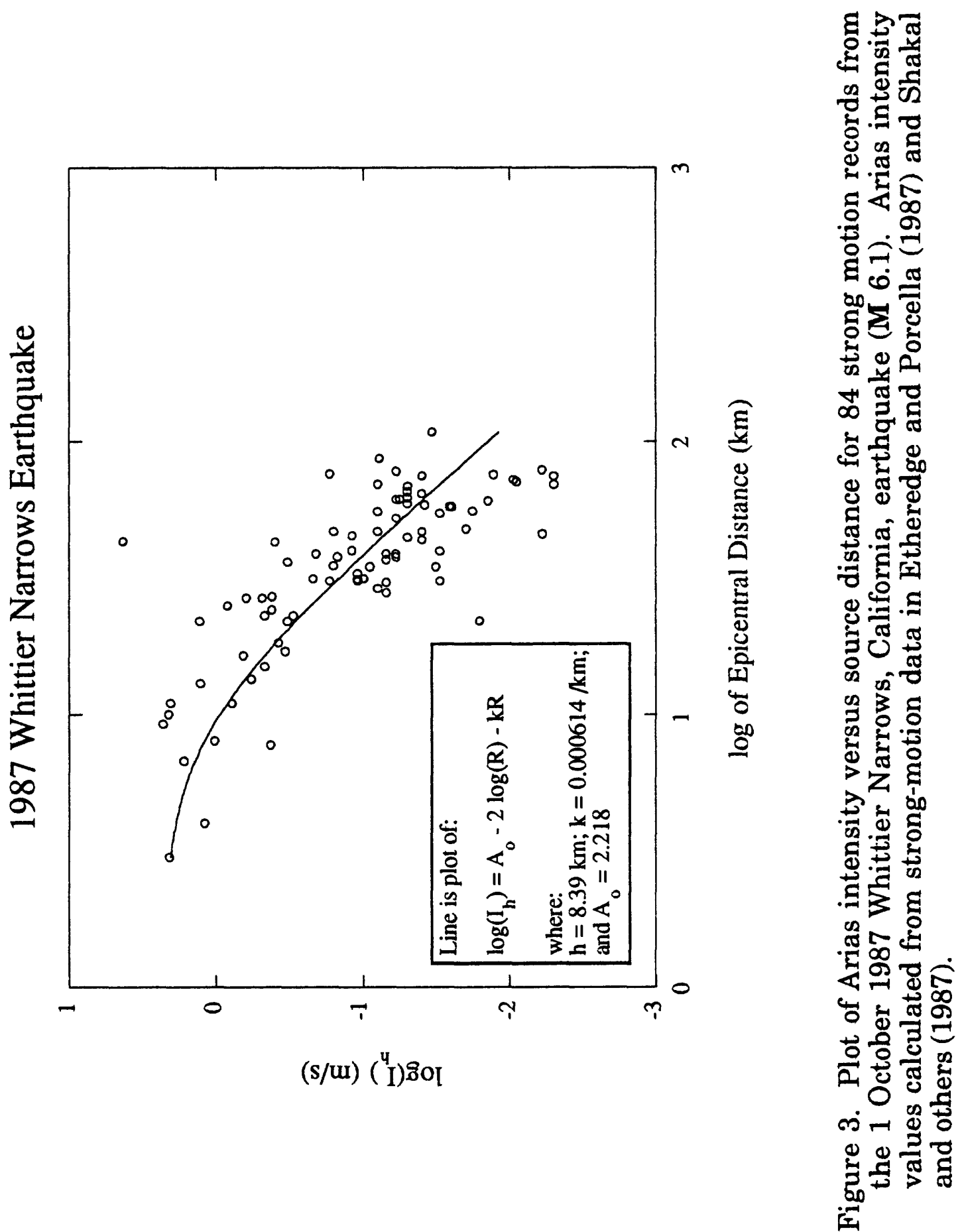
The numerical values of $A_{0}, h$, and $k$ were estimated for each earthquake using a commercial, nonlinear, least-squares, curve-fitting program. These values are shown on the plots (figures 1,2 , and 3) and listed in table 1, along with these parameters found by a similar process for seven other California earthquakes. As shown in the attenuation plots (figures 1,2 , and 3 ), the curves plotted from these parameters bisect the field of plotted data points symmetrically. The slopes of the curves $(-2$ for D $>>h$ ) appear to be roughly parallel to both the upper and lower limits of the fields of data points. The residuals, resulting from subtracting values of $I_{h}$ predicted by the fitted curves from the $I_{h}$ values actually observed, appear to be normally distributed and independent of either the magnitude or the source distance (residuals are discussed further in a following section).

Other combinations of values of the empirical parameters, $A_{0}, h$, and $\mathrm{k}$, are possible, of course, especially if the geometric spreading parameter is also allowed to vary from a value of two (i.e., $2 \log (R)$ ), yielding similar, or very slightly lower, residual sums-of-squares. However, curves plotted from these general combinations virtually coincide with the inverse-square curves shown in figures 1,2 , and 3 . Seismic attenuation purely by geometric spreading, in fact, requires a fixed value of the spreading parameter: either a value of one, for peak acceleration or peak velocity, or a value of two, for Arias intensity. For purposes of understanding the physical processes of seismic attenuation, there is really no rationale for seeking a purely statistical solution to the value of the spreading parameter.

Any variance in seismic attenuation from pure geometric spreading should be described by the value of the anelastic absorption parameter, $k$. The numerical evaluations for the absorption parameter, $\mathrm{k}$, while poorly constrained, are certainly very small (table 1 ). Several events yielded zero or negative values for $k$; the negative values were ignored and a value of zero was used in these curve-fits. In fact, only very minor adjustments were required for anelastic absorption, and then only for certain events.

\section{Arias Intensity as a Function of Magnitude:}

Continuing with the effort to verify predictions from the theoretical model against actual strong-motion data, the log-linear relationship between Arias intensity and the moment magnitude predicted by equation (11) was evaluated by the following procedure, adapted from that of Joyner and Boore (1981): Values of $A_{0}$, the proportionality constant estimated above by fitting an inverse-square relation to attenuation data (table 1), were plotted against moment magnitude for each of ten California earthquakes and a least-squares linear regression line was calculated (figure 4). The range in moment magnitude for the data set extends from M 5.3 (1957 Daly City) to M 7.5 (1952 Kern County). Error bars corresponding to one standard deviation are also plotted for each value of $A_{0}$. 

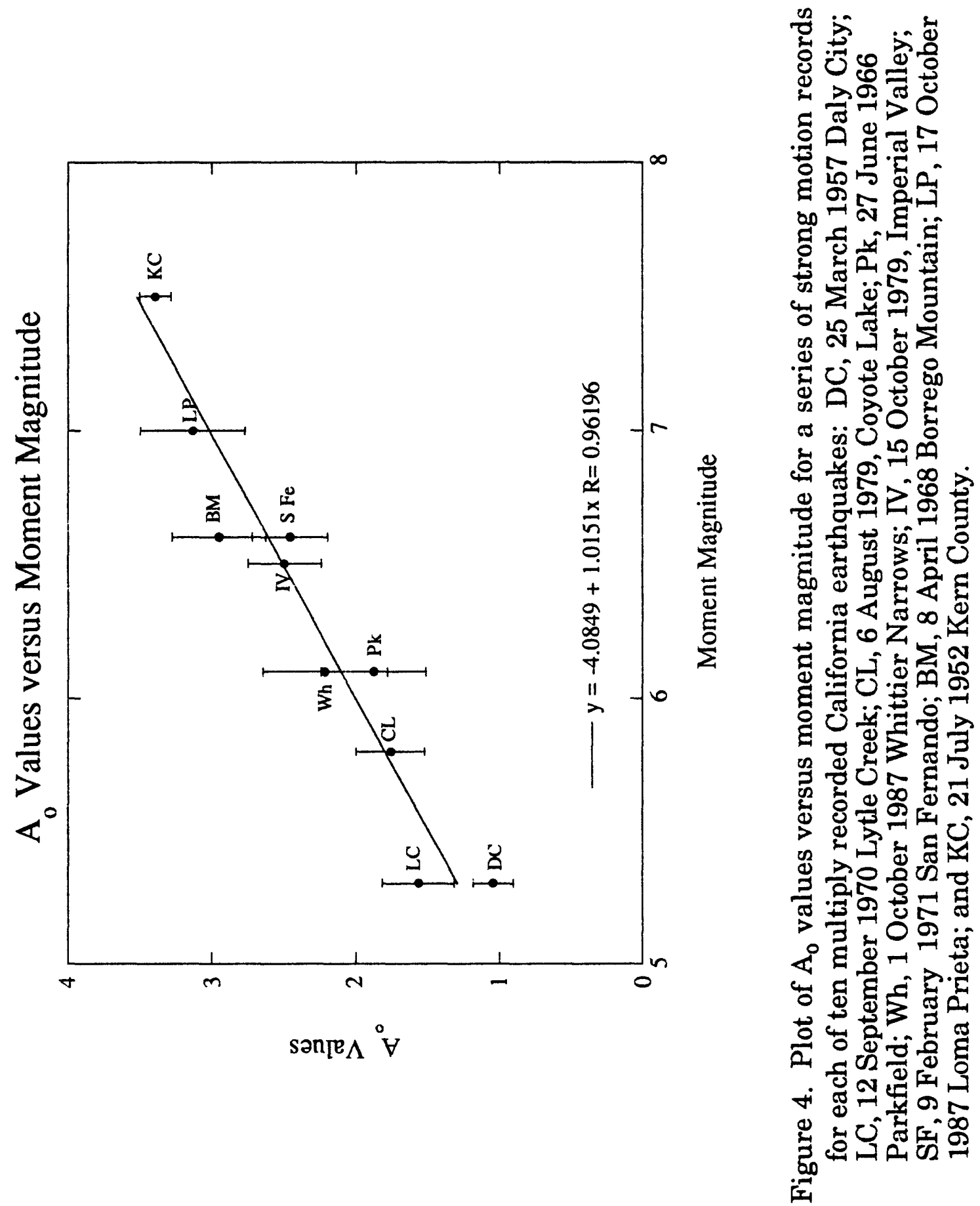
The slope of the regression line is 1.0151 , compared to the value of exactly one predicted by the theoretical relation (equation 11). The standard deviation for the slope term in the regression is 0.1019 , so the deviation from the predicted value is trivial. If the slope of the $A_{0} / M$ regression line is adjusted to be exactly one, then the proportionality constant will become equal to the mean of $\left(A_{0}-M\right)$, which is 3.990 , with a standard deviation of 0.204 . This value closely agrees with the constant in equation 11 , suggesting that the stress drop is well-constrained around a common value, approximately 100 bars, at least for earthquakes in California within the magnitude range in the data set. (Because equation 11 is based on a theoretical model where all of the seismic energy is contained in one component, the $I_{a}$ term is equivalent to the $I_{h}$ term in the empirical equation 12 , which sums the energy in the two horizontal components.)

Analysis of Residuals from a Combined Data Set:

Now that the theoretical predictions about the variation of Arias intensity with source distance and with magnitude have been verified by separate tests, the next step is to ascertain how much variation exists in a combined strong-motion data set in which both magnitude and distance vary. This variation must also be analyzed to see what portion results from flaws in the theoretical model and what portion is simply random noise. This may be done by examining the residuals resulting from subtracting the values of Arias intensity predicted from the values of $A_{0}, h$, and $k$ listed in table 1 , from the values of Arias intensity actually observed. The residuals from each of the ten earthquakes listed in table 1 were then pooled together into a common data set.

Figure 5 is a plot of residuals versus horizontal distance, D, for each of the 210 records in the common data set; showing that there is no significant correlation remaining between the distance and the residuals. Figure 6 is a plot of residuals versus moment magnitude and shows that the residuals are independent of $\mathbf{M}$. Finally, figure 7 plots the cumulative distribution of residuals against a probability scale. This plot shows that the distribution of residuals may be fit very well by a normal distribution with a mean of 0.0058 (i.e., a zero mean) and a standard deviation of 0.354 . These results suggest that any consistent errors resulting from flaws in the theoretical model are either negligible or overwhelmed by the random noise that dominates the distribution of residuals. In either case, the simplest model for the distribution of residuals is a normally distributed random variable. 


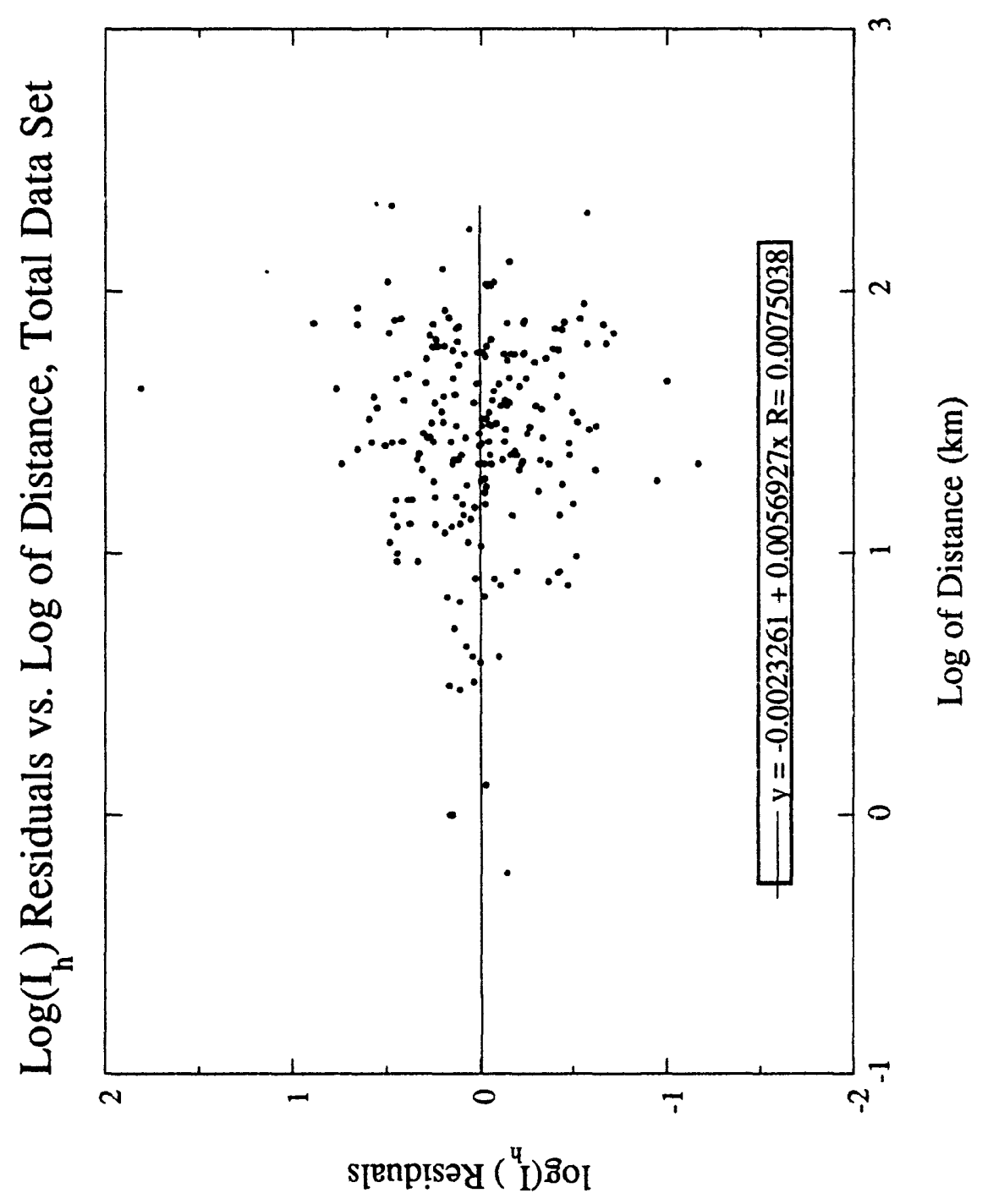

연.

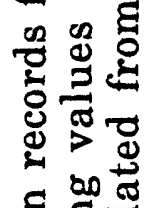

乎

정

유을 क

동 용

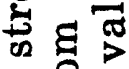

产

온행

N

क्ष

造

또

记.

造

设

哏零

策 $-\dot{4}$

के 응

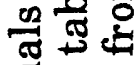

.

on

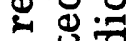

4艹

을 号

可芯至

เ

0 0

․ㅗㅀㅇㅛ

$\infty$ 

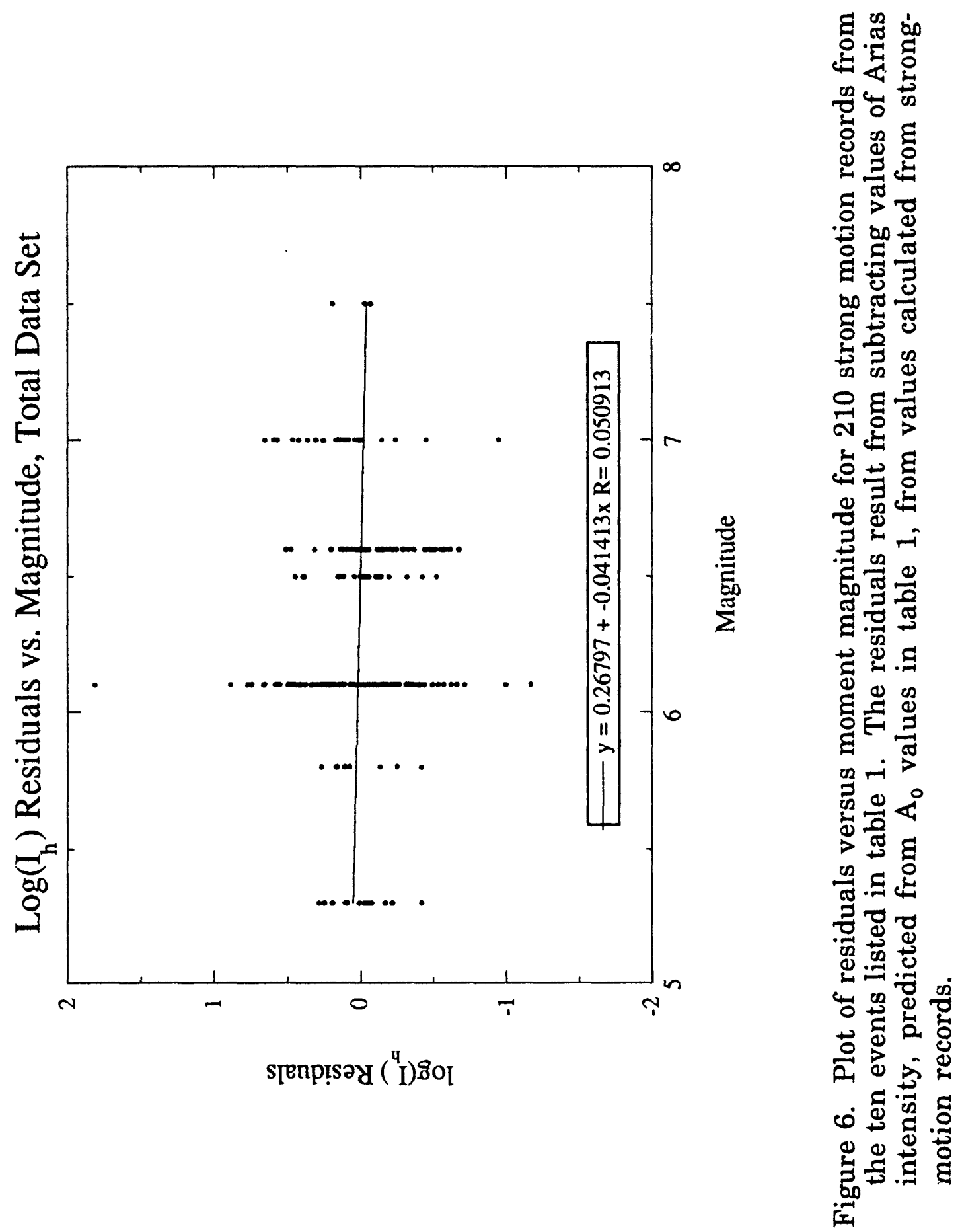


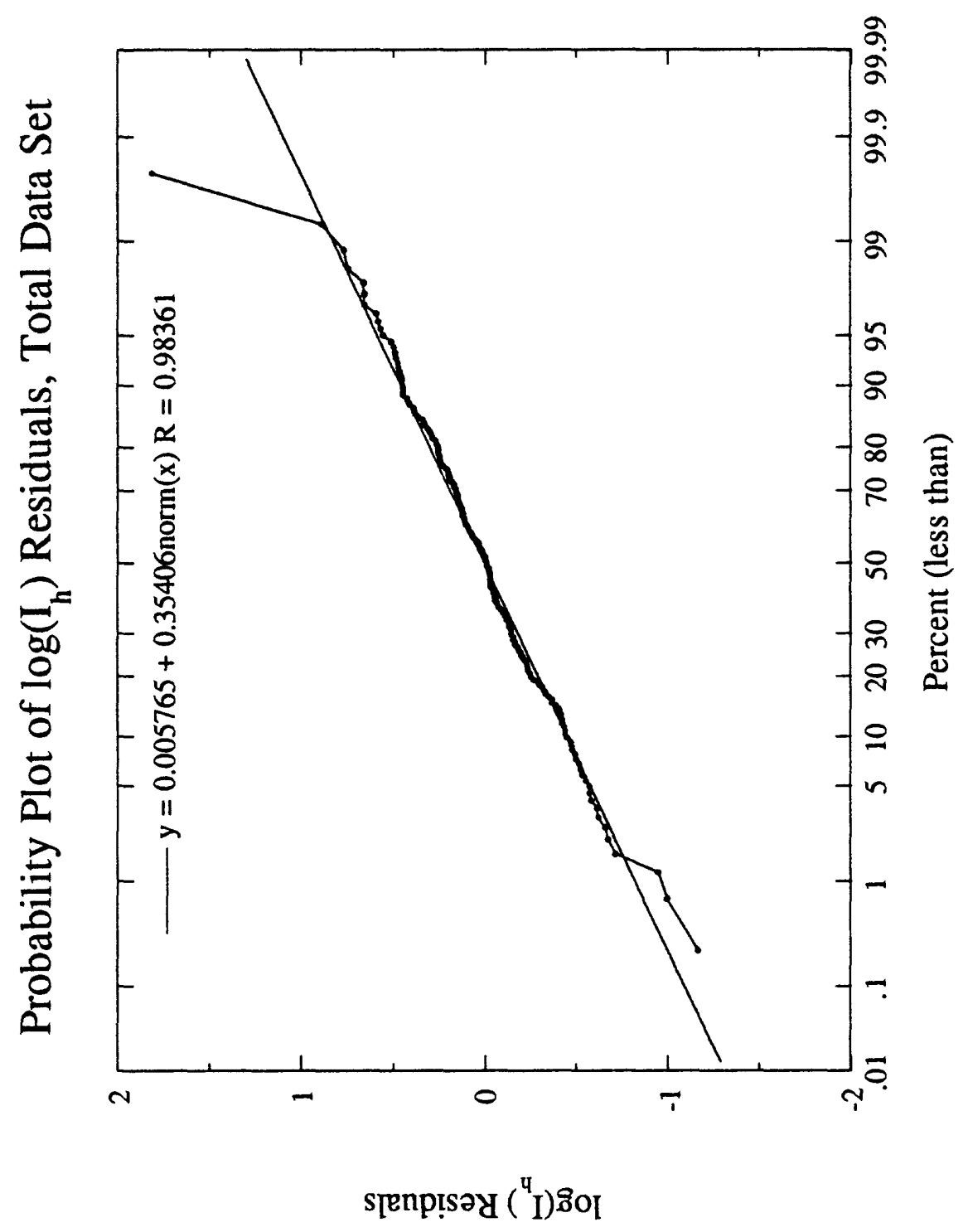

苞高㻤

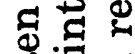

웡. 옹

$\Phi$ 잉

हैँ

40 잉

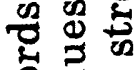

.

娄

ond

दี

刍

중

Q0뮬ㄹ

동

站

으룬룽

空

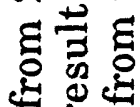

a

อำ

两.

$\Phi$

$+$.

40

음

궁

홍 잉

응

क. $\Xi$

ㄷㅇㅇㅛ

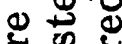

影

空 


\section{A Possible Simplification:}

The residuals analyzed in the previous section were generated using values of $A_{o}, h$, and $k$, based on curve-fitting for individual earthquakes. While exact values for these parameters will not be known in advance, some approximations are possible that may allow reliable predictions of Arias intensities for future events in California. For example, the value of $A_{o}$ may be estimated by subtracting the mean value of $\left(A_{0}-M\right), 3.990$, from the expected moment magnitude. Further, if the ten events listed in table 1 are typical, the distance-correction term, $h$, is generally in the range of 5 to $10 \mathrm{~km}$, and the anelastic absorption term, $\mathrm{k}$, is $0.0015 / \mathrm{km}$ or less. Thus, an approximate value of $7.5 \mathrm{~km}$ for $\mathrm{h}$ should yield acceptable accuracies for expected horizontal distances, D, greater than $10 \mathrm{~km}$, and anelastic absorption should be virtually negligible (i.e., $k=$ zero) for $D$ less than 150 km.

These approximations were used to calculate a new set of residuals from the ten earthquakes in table 1 . The new residuals also show no significant correlation with either $M$ (correlation coefficient $=0.090$ for 210 points) or $\mathrm{D}$ (cor. coef. $=0.102$ ), and exhibit nearly perfect normality (figure 8) with a standard deviation, 0.365 , that is virtually identical to the first set of residuals. Thus, in the range of magnitudes (M 5.3 to 7.5) and source distances $(D=10$ to $150 \mathrm{~km}$ ) in which most of the strong-motion data falls, these generic values of $\mathrm{Ao}, \mathrm{h}$, and $\mathrm{k}$ may be used for predicting Arias intensity values from California earthquakes with a minor increase in uncertainty.

\section{Summary of Empirical Analyses:}

In summary, these empirical analyses indicate that the "best-fit" magnitude/distance relationship for Arias intensity for California earthquakes is,

$$
\log \left(I_{h}\right)=\mathbf{M}-2 \log (R)-k R-3.990+0.365 \mathbf{P}
$$

where, $R=\sqrt{D^{2}+h^{2}}$, and the values of the distance correction factor, $h$, and the coefficient of anelastic absorption, $k$, are either determined for an individual earthquake, or if unknown, set to the generic values $(\mathrm{h}=7.5 \mathrm{~km}$; $\mathrm{k}=$ zero). In the final term, the multiplier $(0.365)$ is equal to the standard deviation of the residuals, and $\mathbf{P}$ is the exceedance probability, in terms of the number of standard deviations above or below the median (probits). This final term expresses the stochastic variation in the Arias intensity due to the random noise inherent in seismic ground motion.

Given the magnitude and the source distance from a postulated earthquake, therefore, this relationship may be used to estimate either the mean value of the Arias intensity or the probability of the Arias intensity exceeding a specified value, and allows an estimate of the statistical confidence of that prediction. 


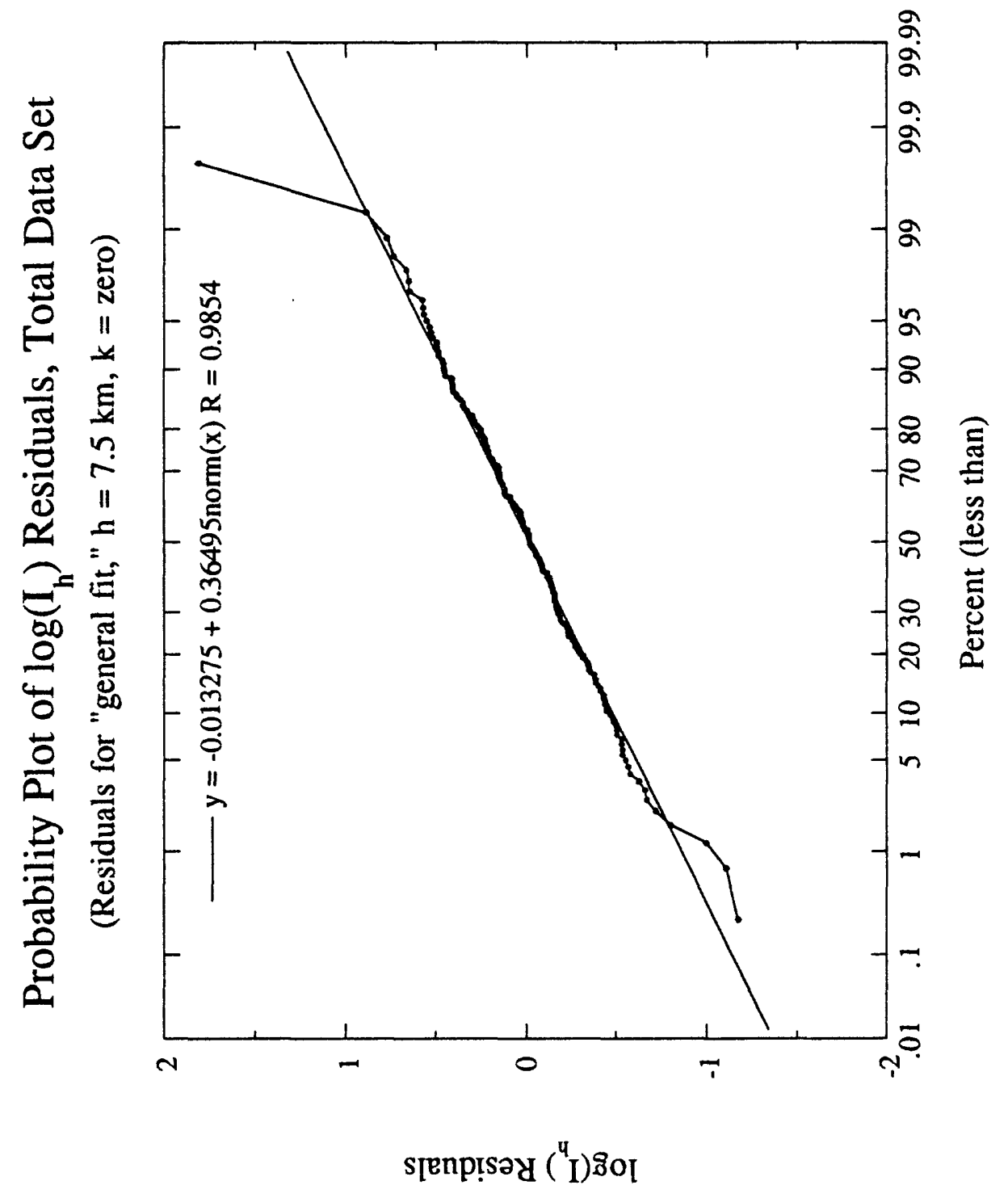

总 吾

동. 氙

$+28$

폰

다응

엉유융

응 옴

엉 일

ల $>$

a o i

옴롱 응

은

a 0 능 엉

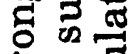

휴 हु

0 융

N

리

눈 $>$

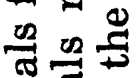

J

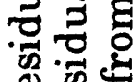

D

4 든

농동

四

걸- 용

흥응 응

응

م. 드 엉

$\infty$ 웡

㻤

近 


\section{MODIFICATIONS OF THE M/R/ $\mathrm{I}_{\mathrm{h}}$ RELATION FOR SPECIAL CONDITIONS}

Site-Response Effects:

A number of authors (e.g. Gutenberg, 1957, Medvedev, 1962, Borcherdt, 1970, Borcherdt and others, 1975) have suggested that the seismic response of the near-surface materials underlying a site may have a strong influence on the seismic intensity, however measured or estimated. Borcherdt and Gibbs (1976), for example, have re-interpreted the intensity distribution in San Francisco from the 1906 earthquake (Wood, 1908) and show a strong correlation between seismic intensity and the geology underlying the site.

However, the quantitative evaluation of the effect of site-response on Arias intensity may be complicated by a number of factors. For example, the influence of the site conditions may be obscured by statistical variations arising from other causes, such as azimuthal variations (discussed below), complexities in the source mechanics, reflections and refraction along the propagation path from source to site, topographic effects, and so forth. Further, site conditions may create some effects that counterbalance others. Compared to a nearby site on bedrock, for example, a site on deep soil may record a longer duration (e.g. Dobry and others, 1978), but smaller accelerations (due to a decrease in $f_{\max }$ ). The longer durations would increase the Arias intensity, the lower accelerations decrease it.

Perhaps the clearest way to demonstrate site-response effects is to compare the Arias intensities at two free-field sites, one on bedrock, the other on soil, that have no other obvious differences and are much closer to each other than either is to the source zone. Discussions of site-response effects, as reflected in strong-motion records, from a number of such paired sites have appeared in the literature, but none specifically discuss Arias intensity. Four paired records were selected for discussion here.

The first pair of records are from the 1979 Coyote Lake earthquake and described by Joyner and others (1981). The Gilroy \#1 site is located on sandstones of the Franciscan formation; Gilroy \#2 is located on Quaternary alluvium, $180 \mathrm{~m}$ thick, overlying the Franciscan bedrock. The Arias intensities calculated here for these two records are $I_{h}=0.160 \mathrm{~m} / \mathrm{s}$ for Gilroy \#1, and $I_{h}=0.680 \mathrm{~m} / \mathrm{s}$ for Gilroy \#2. Because the distance between the two sites $(2 \mathrm{~km})$ is significant compared to the surface source distances (8.4 km for Gilroy \#1 and $6.5 \mathrm{~km}$ for Gilroy \#2), corrected $I_{h}$ values for a common total source distance of $12 \mathrm{~km}$ were calculated, based on the value of $h=8.19 \mathrm{~km}$, listed in table 1 . These corrected $I_{h}$ values $(0.153 \mathrm{~m} / \mathrm{s}$ for Gilroy \# 1 and $0.516 \mathrm{~m} / \mathrm{s}$ for Gilroy \#2) were used to calculate the siteresponse amplification factor of the thick Quaternary alluvium underlying Gilroy \#2, expressed in terms of the difference in $\log \left(\mathrm{I}_{h}\right)$ for the two sites, $\Delta \log \left(I_{h}\right)=0.528$. (A smaller amplification of strong motion was noted for 
these same two sites during the 1989 Loma Prieta earthquake (Darragh and Shakal, 1991)).

The next two pairs of records from rock/soil sites were recorded during the 1989 Loma Prieta earthquake. The first pair, Yerba Buena Island (58163) on Franciscan bedrock, and Treasure Island (58117) on artificial fill over San Francisco bay mud, are about $2.5 \mathrm{~km}$ apart and approximately 80 $\mathrm{km}$ from the source zone. The two sites were installed specifically to record site-response differences by the California Division of Mines Strong Motion Instrumentation Program (CSMIP) about 16 years ago, and triggered for the first time in this event (Darragh and Shakal, 1991). The bedrock site, Yerba Buena Island, recorded an Arias intensity of $I_{h}=0.059 \mathrm{~m} / \mathrm{s}$, and the bay mud site, Treasure Island, recorded a value of $I_{h}=0.509$, for a siteresponse amplification factor, $\Delta \log \left(\mathrm{I}_{h}\right)=0.936$.

The next pair of records, Rincon Hill (58151) and Oakland Wharf (58472) also contrast the response of Franciscan bedrock with San Francisco bay mud, respectively. These two sites are farther apart, $6.9 \mathrm{~km}$, but still reasonably close relative to the source distance, approximately 80 $\mathrm{km}$. The bedrock site, Rincon Hill, recorded an $I_{h}=0.123 \mathrm{~m} / \mathrm{s}$; the bay mud site, Oakland Wharf, $I_{h}=1.712 \mathrm{~m} / \mathrm{s}$, for an amplification factor, $\Delta \log \left(I_{h}\right)=$ 1.144. Some of this amplification, however, may be due to the influence of the wharf structure at the latter site.

The final pair, recorded in Mexico City during the 1985 Michoacan earthquake $\left(\mathrm{M}_{\mathrm{s}}\right.$ 8.1) (Anderson and others, 1986), provide the most dramatic example of site-response amplification of strong ground motion. The bedrock site, UNAM, is located on Holocene basalt flows on the campus of the National University of Mexico, and recorded an Arias intensity of $\mathrm{I}_{h}=$ $0.105 \mathrm{~m} / \mathrm{s}$. This is approximately the value expected for this magnitude ( $M$ $8.0)$ and source distance $(350 \mathrm{~km})$, according to equation (11). The second site, SCT, is located $5 \mathrm{~km}$ away in the compound of the Secretaria de Comunicaciones y Transportes, on very soft, high-water content clays laid down by the former Lake Texcoco, and recorded an $I_{h}=3.257 \mathrm{~m} / \mathrm{s}$. Thus, the site-response amplification factor for the SCT site, underlain by lake clays, compared to the UNAM site,underlain by Holocene basalts, is very large, $\Delta \log \left(I_{h}\right)=1.491$. In fact, while the area surrounding the UNAM site had relatively minor structural damage (MMI VI), many high-rise buildings collapsed (MMI IX) in the downtown area where the seismic shaking was amplified by the old lake beds (Mendoza and Prince, 1986).

In summary, areas underlain by thick alluvium exhibit site-response effects that can cause significant amplification of seismic ground motion, with a consequent increase in the Arias intensity over that predicted for bedrock sites. For sites underlain by soft, low-velocity materials, such as the San Francisco bay mud or the lake-bed clays of Mexico City, these amplifications can reach an order-of-magnitude or more, and can produce 
extremely hazardous conditions in major earthquakes, even at large source distances.

\section{Source Directivity:}

Variations in the strength of seismic shaking as a function of the angle between the source-to-station azimuth and the direction of propagation of the seismic rupture are denoted by the general term, directivity. Such effects may have a dramatic influence on the distribution of energy during an earthquake. Benioff (1955), for example, described an azimuthal variation of approximately an order-of-magnitude in the amplitudes of surface waves from the 1952 Kern County earthquake (M 7.5), with stronger arrivals noted in southern Europe than those at equivalent distances in New Zealand and Australia. Espinosa and others (1976) also described markedly asymmetric seismic intensity patterns from the 1976 Guatemala earthquake $\left(M_{s} 7.5\right)$ and attributed this asymmetry to directivity.

A nearly ideal case for isolating the effects of directivity was described by Boatwright and Boore (1982), in their study of the azimuthal variations in strong ground motion from the 1980 Livermore Valley earthquake sequence. The two largest events of the sequence were both nearly unilateral ruptures that occurred on virtually adjacent segments of the same fault system, but propagated in opposite directions. The M 5.8 event on $1 / 24 / 80$ propagated to the southeast, on a fault striking $\mathrm{N} 37^{\circ} \mathrm{W}$, and the M 5.5 event on $1 / 27 / 80$ propagated to the northwest. Both events were well recorded over a broad range of azimuths.

Boatwright and Boore (1982) calculated the ratios of peak accelerations recorded from the two events at a number of strong-motion stations distributed across $270^{\circ}$ of azimuth from the zone of energy release, and found that these ratios were well fit by a directivity function,

$$
D S(\psi)=(1-\Delta v / \beta \cos \psi)^{-1}
$$

where $\psi=$ angle between direction of rupture and the source-to-site direction; $\Delta v=$ the change of rupture velocity associated with radiation of the seismic pulse, and $\beta=$ shear wave velocity at the seismic source.

Boatwright and Boore (1982) also calculated root-mean-square accelerations and durations for both events at nine of the permanent strong-motion stations. These values were used in this study to calculate the Arias intensities $\left(I_{a}\right)$ for these records. The $I_{a}$ values were then normalized to a common magnitude (M 5.5) and distance $(25 \mathrm{~km})$, and divided to form ratios (1/24/80 over 1/27/80). Finally, these ratios were plotted against absolute azimuth, $\theta$, in figure 9 . 

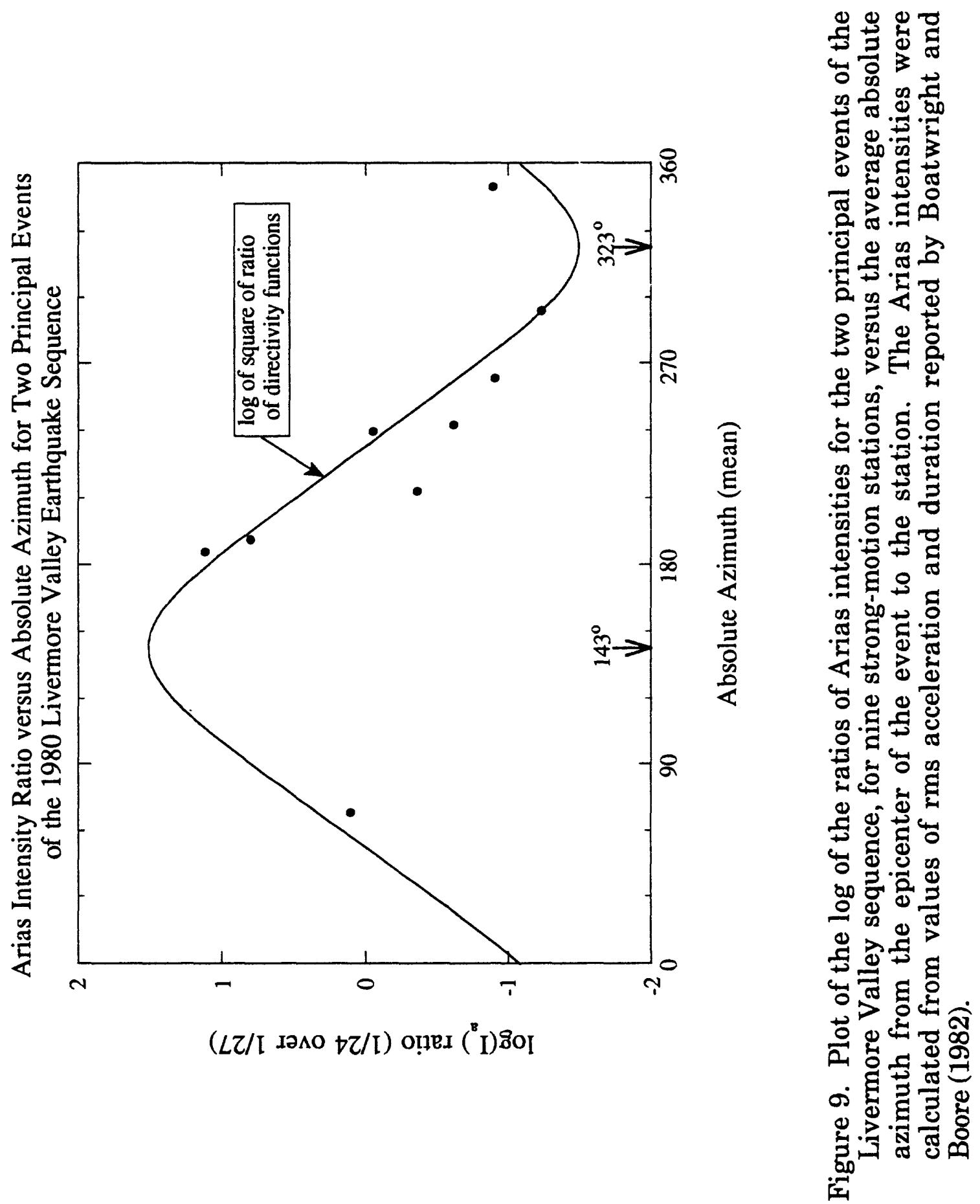
This plot shows a clear relationship between the absolute azimuth and the Arias intensity ratios for the two events, with a maximum ratio in a southeast direction parallel to the fault $\left(\theta=143^{\circ}, \psi=180^{\circ}\right)$. The Arias intensity ratios appear to be reasonably well approximated by a curve equal to the ratio of the squares of the directivity functions, with a value of the propagation velocity ratio $\Delta v / \beta=0.70$. This curve predicts variations in the value of $I_{a}$ of more than an order of magnitude.

Although less common than the site-response effects discussed above, source directivity can create large variations in the value of Arias intensity above or below those predicted by equation (11), and thereby significantly influence the distribution of seismic shaking damage and ground failures. While rarely considered at present, source directivity effects should be incorporated in regional planning or seismic engineering design.

Relations Between Site Effects, Directivity, and Stochastic Variations:

Site-response and directivity effects are deterministic, at least in principle. How are they related to the apparently stochastic variations in Arias intensity described by the log-normally distributed residuals illustrated in figures 5 through 8 ? While both site-response and directivity effects obviously contribute to the residual variations, other effects also probably contribute to an unknown extent, such as elastic scattering of seismic waves from crustal heterogeneities. Furthermore, in most earthquakes, the existence or extent of site-response and directivity effects are poorly known. Figures 5 through 8 make it clear, however, that realworld strong-motion data contain significant variability which can be described fairly well with a simple log-normal relation. The determination of how much of this variation is deterministic in theory, but unknown in practice, and how much is truly random, must await further studies.

\section{PREDICTING EARTHQUAKE-INDUCED LANDSLIDES}

An example of an application for the Arias intensity relationships developed here is the prediction of limiting distances for the occurrence of landslides that could be triggered by a postulated earthquake. Earlier studies have shown that accurate characterization of the variations in strength of seismic shaking across a region is crucial to the prediction of earthquake-induced landslides. From a study of historical accounts of 40 earthquakes, world-wide, Keefer (1984) made plots of the maximum distance from the fault rupture zone to landslides for each of three broad categories of landslides: (1) coherent landslides (slumps and block slides), (2) disrupted landslides (rock and soil falls, slides and avalanches), and (3) lateral spreads and flows. Using a relatively small strong-motion data set (30 records), Wilson and Keefer (1985) developed an empirical magnitude/distance relationship for Arias intensity, then combined it with 
the historical data set of magnitudes and limiting distances (Keefer, 1984), to find the minimum (threshold) values of seismic shaking severity (as measured by $\mathrm{I}_{\mathrm{a}}$ ) required to trigger each of these categories of landslides from susceptible slopes.

The method used by Wilson and Keefer (1985) is illustrated and updated in the present paper by estimating the threshold value of $I_{h}$ required to trigger falls, disrupted slides or avalanches from susceptible slopes. This category of landslide is selected because it appears to be the most widespread and the most susceptible to triggering by seismic shaking (Keefer, 1984). The historical data is shown in figure 10, where the maximum distance to significant disrupted landslides is plotted against the magnitude of the triggering event (Keefer, 1984). The threshold value of $I_{h}$ and the numerical values of the attenuation parameters, $h$ and $k$, were estimated from the historical data points using a commercial, nonlinear, least-squares, curve-fitting program.

The best-fit threshold value for the Arias intensity was found to be $I_{h}=$ $0.10 \mathrm{~m} / \mathrm{s}$. The magnitude/distance line corresponding to this value of $\mathrm{I}_{\mathrm{h}}$ bisects the field of plotted historical data points, and all but one of the historical data points are contained within lines corresponding to exceedance probabilities of $2 \%$ and $98 \%$ (two standard deviations above and below the median, respectively). The exceptional point corresponds to the 1964 Prince William Sound, Alaska event (M 9.2), for which the reported areal limits of disrupted slides and falls may have been limited by geographical, rather than seismological, factors (Keefer, unpub. data).

This procedure may also be reversed and used to estimate the source distances from a postulated earthquake for which the probability of the seismic shaking severity exceeding these threshold values would be $50 \%$ (corresponding to the median value predicted for $\mathrm{I}_{h}$ ) or, $2 \%$ (corresponding approximately to the historical limiting distance). Taking $I_{h}=0.10 \mathrm{~m} / \mathrm{s}$ as the threshold shaking severity for falls and disrupted slides, the median distance would be, approximately, $50 \mathrm{~km}$ for a $\mathbf{M} 6.5$ event. The historical limiting distance for the same event would be $110 \mathrm{~km}$. For a $\mathbf{M} 6.5$ event, therefore, the areal limit of disrupted landslides on susceptible slopes would have a greater than even chance of extending at least $50 \mathrm{~km}$ from the source zone; a somewhat less than even chance of extending between 50 and $110 \mathrm{~km}$; and would be highly unlikely to extend beyond $110 \mathrm{~km}$ from the source zone, even for highly susceptible slopes.

\section{CORRELATION OF ARIAS INTENSITY WITH THE MODIFIED MERCALLI SCALE}

Over the past half-century, numerous attempts have been made to establish a correlation between non-instrumental seismic intensity scales, such as the Modified Mercalli Intensity (MMI) scale, with various 


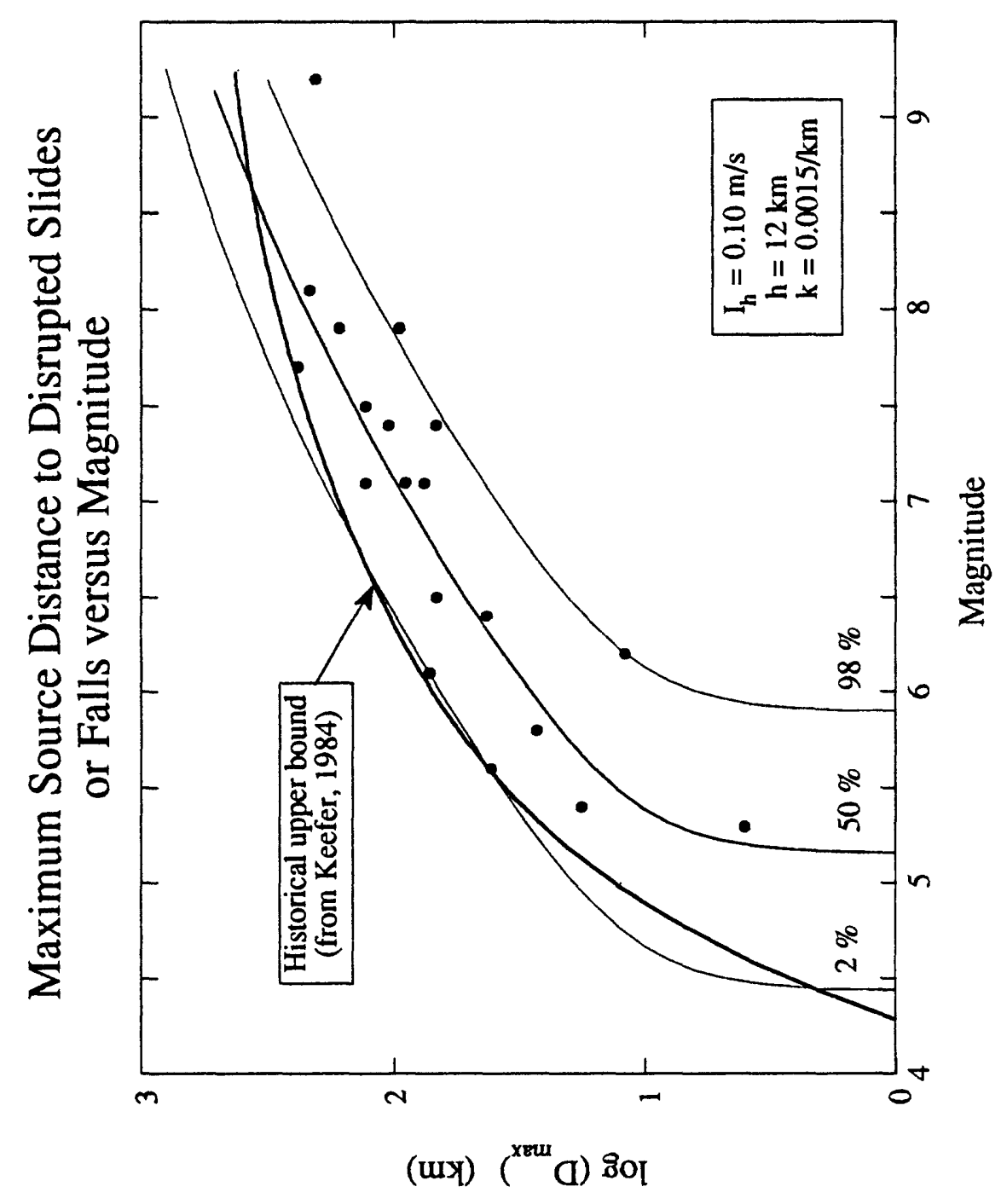

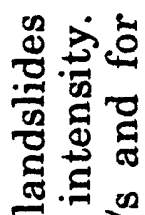

उ. क छ

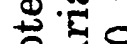

원웅

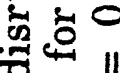

ธี.ํํ도

市 $\frac{\pi}{0}$

今

용

क

ष

$\Phi .2$

궁

웡

$\pm$

कृ

o)

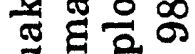

구웜

㝴焉

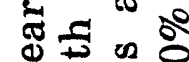

บ

政

ํำ

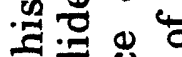

पै

무

ธี สี

क

요

름 공

हี

ठ

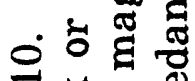

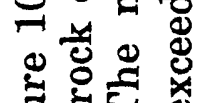

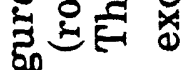

II 
instrumental parameters from a steadily growing collection of strongmotion records. For example, Gutenberg and Richter (1942) developed a correlation between the MMI value, $\mathrm{I}_{\mathrm{mm}}$, and the logarithm of the peak acceleration, $\mathrm{A}$, in $\mathrm{cm} / \mathrm{sec}^{2}$ :

$$
I_{m m}=3(0.5+\log (A))
$$

While this correlation appears convincing with the sparse data set used by Gutenberg and Richter, it tends to degrade substantially as newer data is accumulated (Ambraseys, 1974).

Arias (1970, p. 463) plotted his intensity parameter for 15 strong-motion records against their corresponding MMI values (which he termed, "a psychophysical variable") and calculated a linear regression between the MMI grade $\left(\mathrm{I}_{\mathrm{mm}}\right)$ and the $\log \left(\mathrm{I}_{\mathrm{h}}\right)$ values:

$$
\mathrm{I}_{\mathrm{mm}}=7.25+0.89 \log \left(\mathrm{I}_{\mathrm{h}}\right)
$$

with a correlation coefficient equal to 0.57 (for 13 degrees of freedom (d.f.)), and confidence limits (at the 95\% level) of 6.71 to 7.80 "for the free term", and 0.13 to 1.65 for the slope term. Arias noted further, "It is seen that, although the correlation is significant, the confidence limits for the regression line are very wide."

In this study, another attempt is made to investigate the relation between Arias intensity and the Modified Mercalli scale, using a larger data set of values of $\mathrm{I}_{\mathrm{h}}$ versus MMI from five well-recorded California earthquakes: 1971 San Fernando, 1979 Coyote Lake, 1979 Imperial Valley, 1987 Whittier Narrows, and 1989 Loma Prieta (table 1). (MMI values for the other earthquakes listed in table 1 are too few and/or too poorly constrained to be included in this analysis.)

The analytical procedure followed is similar to that used by Trifunac and Brady (1975) to correlate peak acceleration with MMI grade: Values of Arias intensity were collected for all records with a given MMI value, and the mean and the standard deviation of $\log \left(\mathrm{I}_{h}\right)$ were calculated for each MMI value (Table 2). Finally, the mean values of $\log \left(I_{h}\right)$ were plotted against the corresponding MMI grade, and linear regressions were calculated.

Figure 11 is a plot of $\log \left(I_{h}\right)$ versus MMI grade for 84 strong-motion records from the 1987 Whittier earthquake (M 6.1), the best recorded of the five earthquakes in table 2. MMI values were matched with individual strong-motion records by comparing the instrument locations (Etheridge and Porcella, 1982, and Shakal and others, 1987) to the MM isoseismals mapped by Leyendecker and others (1988). Figure 11 also displays a linear regression of $\log \left(I_{h}\right)$ on $M M I$, which nearly bisects the clusters of data for MMI grades V, VI and VII. 
Table 2. Arias Intensity and Modified Mercalli Intensity.

MMI grade $\begin{gathered}\text { Number of } \\ \text { Records }\end{gathered} \quad$ Mean of $\log \left(I_{h}\right) \quad \begin{gathered}\text { St. Deviation of } \\ \log \left(I_{h}\right)\end{gathered}$

1971 San Fernando Earthquake (M 6.6):

$\begin{array}{lrrr}\text { V } & 6 & -1.103 & 0.584 \\ \text { VI } & 18 & -0.647 & 0.455 \\ \text { VII } & 18 & -0.174 & 0.312\end{array}$

1979 Coyote Lake Earthquake (M 5.8)

$\begin{array}{llll}\text { IV } & 1 & -1.013 & (\mathrm{~N} / \mathrm{A}) \\ \text { V } & 2 & -1.080 & 0.391 \\ \text { VI } & 4 & -0.748 & 0.297 \\ \text { VII } & 4 & -0.035 & 0.120\end{array}$

1979 Imperial Valley Earthquake (M 6.5)

$\begin{array}{llrl}\text { IV } & 1 & -1.055 & (\mathrm{~N} / \mathrm{A}) \\ \text { V } & 7 & -0.526 & 0.287 \\ \text { VI } & 5 & 0.215 & 0.206 \\ \text { VII } & 9 & 0.363 & 0.247\end{array}$

1987 Whittier Narrows Earthquake (M 6.1)

$\begin{array}{lrrr}\text { IV } & 6 & -1.190 & 0.255 \\ \text { V } & 44 & -1.346 & 0.511 \\ \text { VI } & 25 & -0.552 & 0.485 \\ \text { VII } & 8 & 0.106 & 0.253 \\ \text { VIII } & 1 & 0.326 & (\mathrm{~N} / \mathrm{A})\end{array}$

1989 Loma Prieta Earthquake (M 7.0)

$\begin{array}{lrrr}\text { VI } & 1 & -0.180 & (\mathrm{~N} / \mathrm{A}) \\ \text { VII } & 19 & -0.232 & 0.486 \\ \text { VIII } & 6 & 0.550 & 0.242\end{array}$



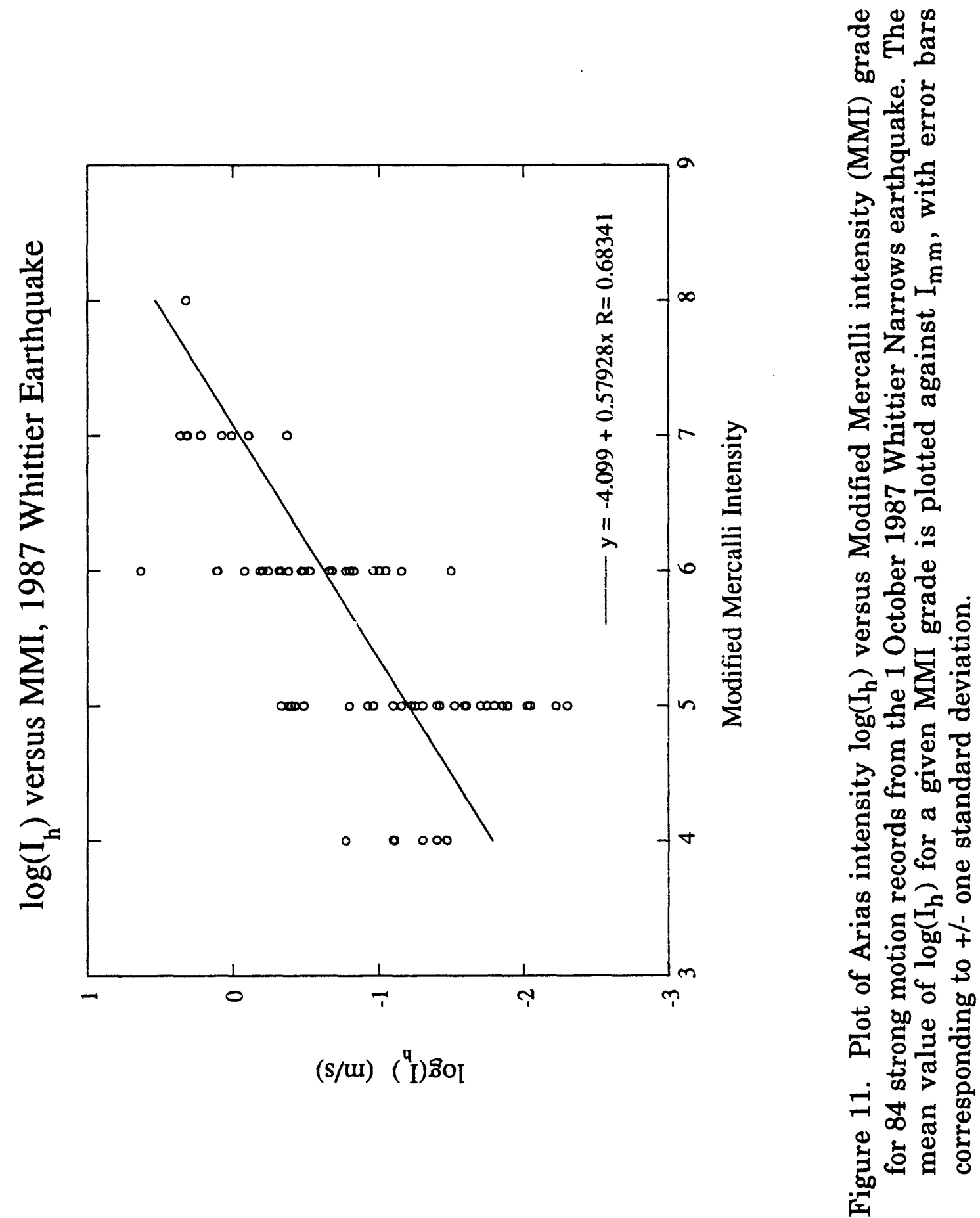
While a significant correlation exists between Arias intensity and MMI grade (cor. coef. $=0.683$ for $41 \mathrm{~d}$. f.), figure 11 also shows a great deal of scatter in the value of $I_{h}$ within a given MMI grade--up to two orders of magnitude for grades V and VI. Further, the distribution of $I_{h}$ values for a given MMI grade overlaps those of adjacent grades, and even, to a lesser extent, MMI grades two steps removed.

The regression line underestimates the $\log \left(I_{h}\right)$ values collected for grade IV and overestimates the single $\log \left(\mathrm{I}_{h}\right)$ value for grade VIII. However, the MMI IV data set may be biased because not all of the strongmotion instruments in this zone were triggered by the event. Also, in light of the scatter evident in the $\log \left(\mathrm{I}_{h}\right)$ data for grades $\mathrm{V}$ to VII, the single Arias intensity value for MMI grade VIII is reasonably close to the regression line.

Figure 12 is a combined plot of $\log \left(\mathrm{I}_{h}\right)$ values collected for each MMI grade for all of the five earthquakes listed in table 2. For four of the five well-recorded events in table 2, there appears to be good overall agreement between the distribution of $\log \left(\mathrm{I}_{h}\right)$ values versus MMI grade, with a relatively uniform increase in the mean values of $\log \left(\mathrm{I}_{h}\right)$ between MMI grades V through VIII. (MM IV may be biased by accelerographs that were not triggered.) The exceptional event is the 1979 Imperial Valley earthquake, with data (marked by a special symbol) that are clearly skewed toward the upper ends of the clusters of $\log \left(\mathrm{I}_{h}\right)$ data defined by the other four events. (These data are plotted separately in figure 13 and discussed further, below.)

Figure 12 also displays linear regressions for $\log \left(I_{h}\right)$ versus MMI for the combined data set for four earthquakes in table 2 (lower line) and for data from the 1979 Imperial Valley earthquake (upper line). The regression equation for $\log \left(\mathrm{I}_{h}\right)$ versus MMI from the data collected from the four combined events (lower line) is,

$$
\log \left(I_{h}\right)=0.527 I_{m m}-3.816
$$

The standard deviations of the two regression parameters are 0.037 for the slope term and 0.223 for the proportionality constant. The correlation coefficient is 0.748 (for 161 d.f.s). Also, the Arias intensity values collected for MMI grades V, VI, and VII in the four combined events appear to be lognormally distributed (figure 14). 


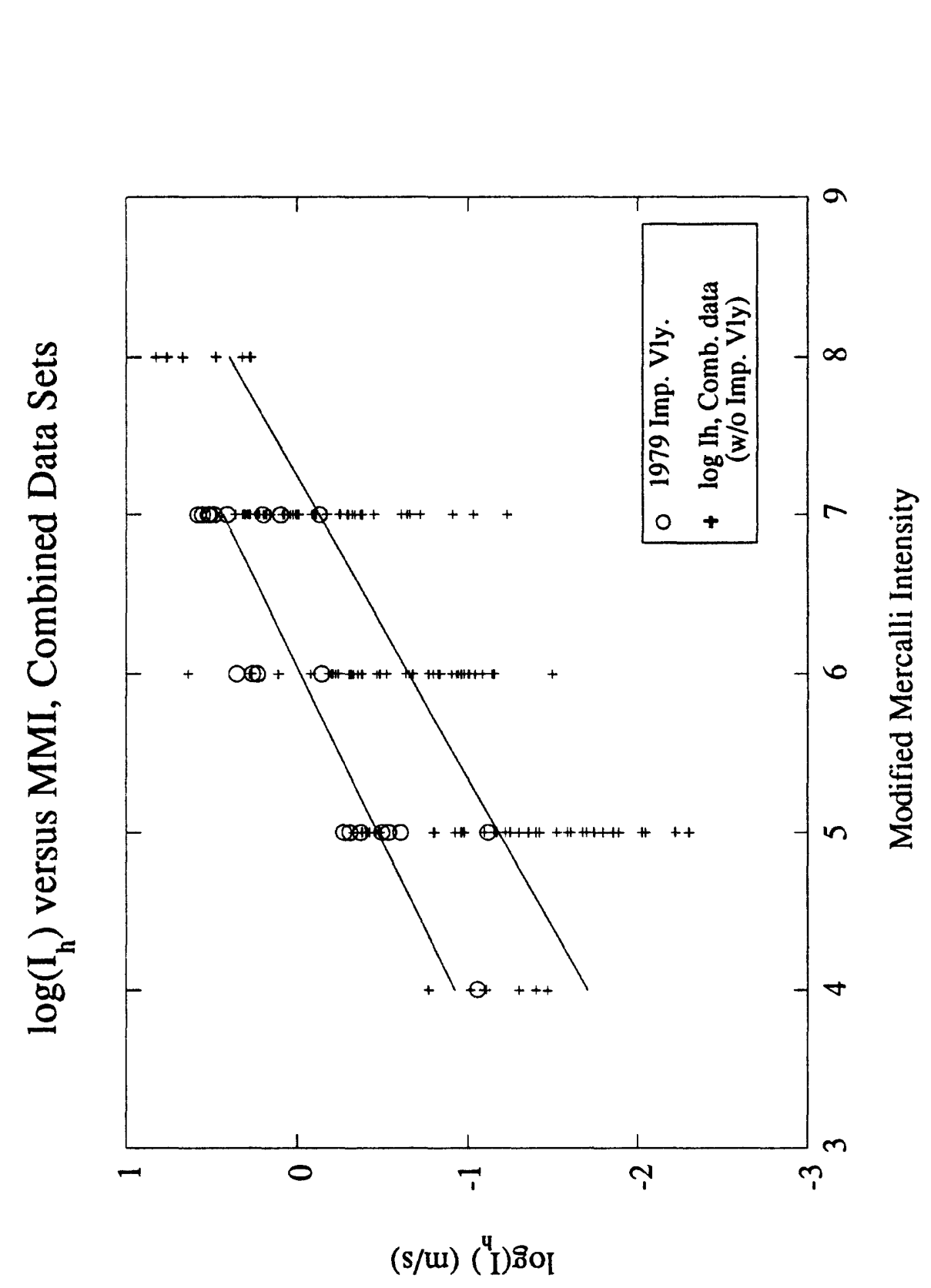

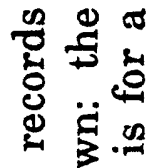

동 屯્

엄크

열 형

कू \&

옹

昶寻

造. 욤

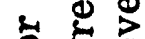

용

용 일

ख त

5o $4 P$

수

$\sum 0=$

o 응

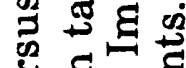

踪

$>$ 둥

도 엄

응

앙 에 언

경형

.

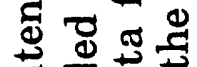

퓽

๘

嵌步吉

4

응

$\bar{\alpha} \dot{0}$

ง

งิ

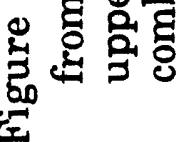



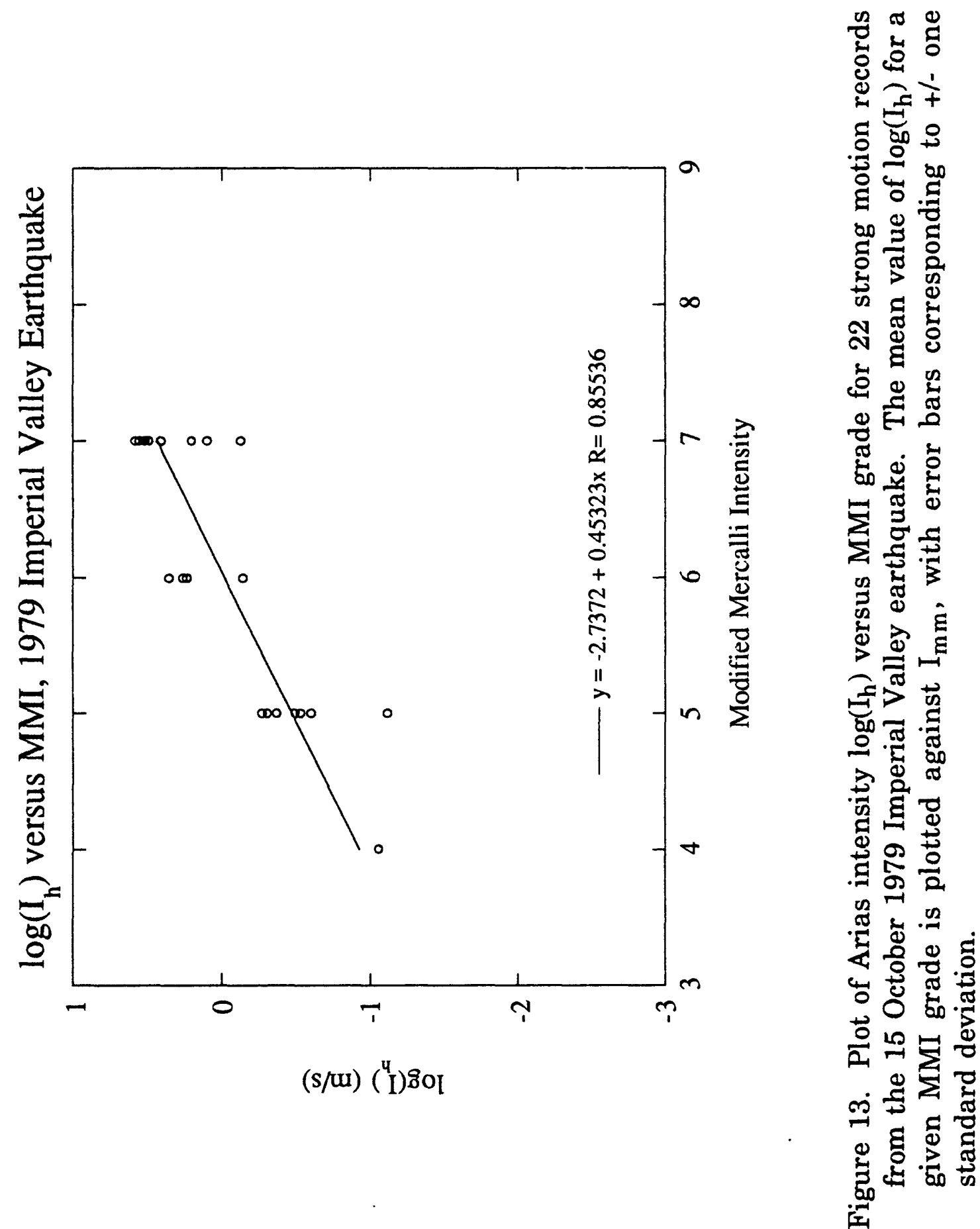

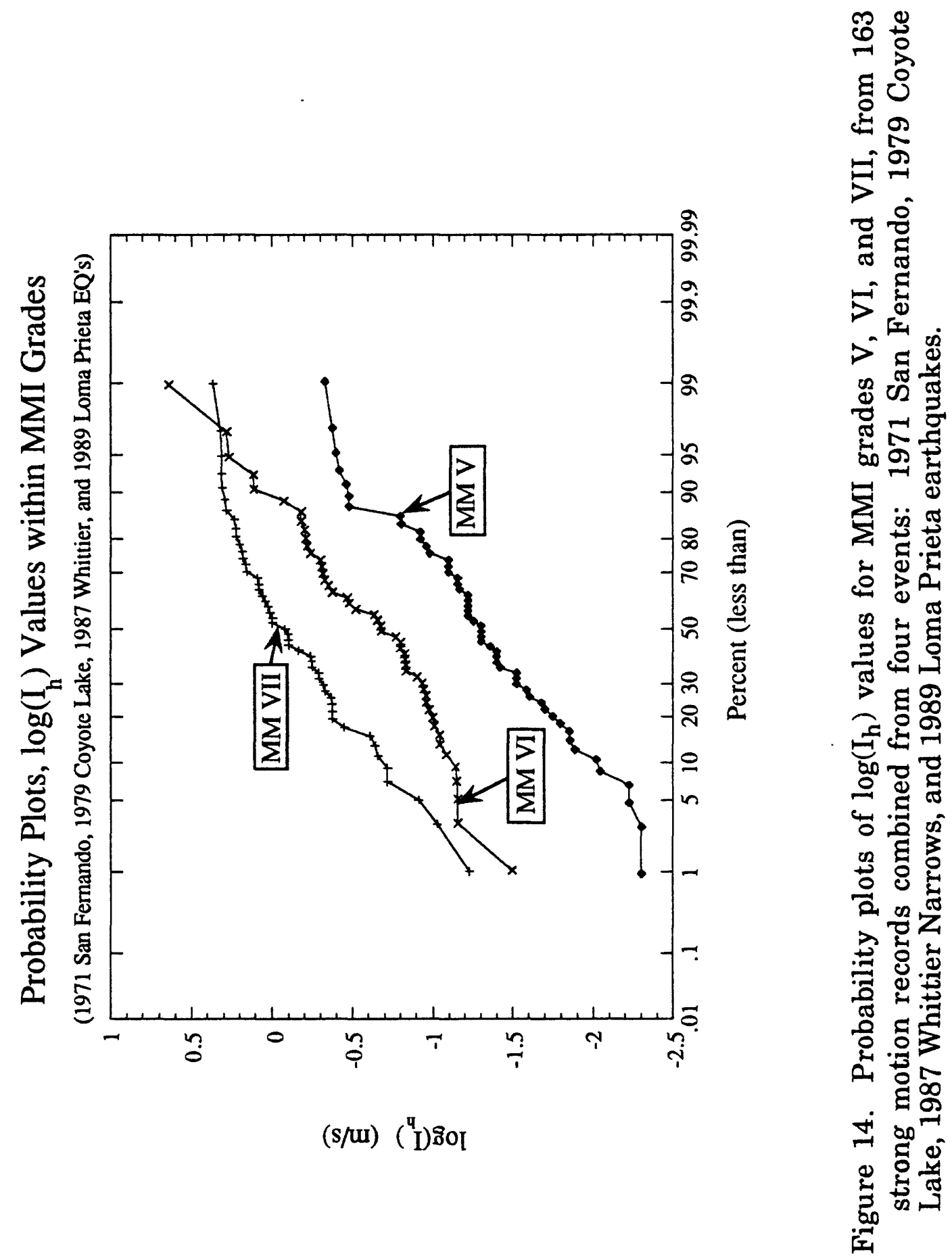
Re-evaluation of Arias's MMI/log $\left(I_{h}\right)$ Regression:

Equation 14 should not be compared directly to the $M M I / \log \left(\mathrm{I}_{h}\right)$ relation of Arias (1970), described above, because Eq. (14) is a least-squares regression of $\log \left(\mathrm{I}_{h}\right)$ on MMI, while the Arias relation is a least-squares regression of MMI on $\log \left(\mathrm{I}_{h}\right)$. (Least-squares regressions are noncommutative for data sets with imperfect correlations--that is, where the correlation coefficient $<1.00$.) To permit a direct comparison with the Arias relation, a regression of MMI on $\log \left(\mathrm{I}_{\mathrm{h}}\right)$ was made, using the same data set as equation 14 ,

$$
I_{m m}=1.063 \log \left(I_{h}\right)-6.686
$$

with a correlation coefficient equal to that of eq. 14 ( 0.748 for 161 d.f.), and confidence limits (at the $95 \%$ level) of 6.54 to 6.83 for the constant, and 0.92 to 1.21 for the slope term. A comparison of equation 15 to the Arias relation indicates agreement of both constant and slope terms within the confidence limits of both relations. While the confidence limits for equation 15, based on 163 data pairs, are much closer than those estimated by Arias, based on only 15 pairs, there is still significant uncertainty in the slope term.

Beyond the ambiguity expressed by the confidence limits, looms the larger question of which of the two (non-commutive) regressions should be considered the correct relationship between Arias intensity and the Modified Mercalli scale. Equation 15 estimates the MMI grade from a value of $\log \left(I_{h}\right)$. Equation 14 estimates the mean value of $\log \left(I_{h}\right)$ within a given MMI isoseismal area. Because they have identical correlation coefficients, both regressions are equally significant statistically. Both relations make predictions of the dependent variable such that the sum of squares of the residuals are minimized. Because of the stochastic nature of both the Arias intensity and Modified Mercalli data sets, neither expression should be considered entirely accurate.

The 1979 Imperial Valley Event; an Anomaly?

Figure 13 is a plot of $\log \left(I_{h}\right)$ versus MMI grade for 22 strong-motion records from the 1979 Imperial Valley earthquake (M 6.5). Individual strong-motion records were matched with MMI values by comparing the instrument locations (Porcella and others, 1982) to MM isoseismals or MMI estimates for small communities and other spot locations (Reagor and others, 1982). Given the scatter in the data, the slope of this regression is not significantly different than that for the 1987 Whittier event (fig. 11), but the proportionality constant is significantly higher.

The unusually high values of Arias intensity versus MMI for the 1979 Imperial Valley event can also be seen by comparing its mean values of 
$\log \left(I_{h}\right)$ versus MMI grade to those of the other four earthquakes (table 2). For example, for MMI VI, $\log \left(\mathrm{I}_{\mathrm{h}}\right)=+0.215$ for the 1979 Imperial Valley event versus -0.552 for the 1987 Whittier event, a difference of 0.767 , corresponding to a factor of nearly six times in the arithmetic value of Arias intensities between the two events. Similar disparities between Imperial Valley and the other events can also be seen in the mean $\log \left(I_{h}\right)$ values for MMI grades V and VII (table 2).

Inspection of the $\log \left(\mathrm{I}_{\mathrm{h}}\right)$ values versus distance (figure 2) and their relation to the magnitude (figure 4) show nothing unusual in the distribution of Arias intensity for the 1979 Imperial Valley event. It is therefore unlikely that the anomalously large $\log \left(\mathrm{I}_{h}\right)$ values versus MMI grade were produced by a deviation in the distribution of ground motion caused by a low stress drop or unusually high anelastic absorption. Rather, it appears that the anomaly is due to the fact that the MM VI and VII isoseismal areas are extremely small for an earthquake of this magnitude (Espinosa, 1982).

A number of possible explanations exist for the unusually small isoseismal areas in the 1979 Imperial Valley earthquake, including: (a) the population was concentrated into a narrow band along the axis of the valley, (b) many of the structures were constructed or rebuilt after a larger (M 7.0) earthquake in 1940 and may be more resistant to damage than would be typical for the class of structures described by the Modified Mercalli scale (e.g. Richter, 1958, p. 136-137), or finally, (c) the MMI grades may have been underestimated in preparing the isoseismal map. While the last explanation is the most tempting, it is probably the least likely. In addition to Reagor and others (1982), other investigators (e.g., Nason, 1982; Wosser and others, 1982) evaluated the structural damage from this earthquake and also noted that it was much less than expected for the size of the event. At this time, it is still unclear why the 1979 Imperial Valley earthquake has such an anomalous relation between Arias intensity and the Modified Mercalli Intensity.

\section{The Ih/MMI Relation. Still Ambiguous:}

It is highly probable that the relationship between Arias intensity (or any other instrumental seismic parameter) and the Modified Mercalli intensity scale (or any other intensity scale based on anecdotal evidence) is far more complicated than can be described by a simple linear correlation. The anecdotal intensity scales are based on the effects of ground motion on people, household objects, structures, and the ground itself. The occurrence of these effects depends on more than simply the distribution of ground motion: They also depend on the distribution of the people and objects affected, and on the probability, within randomly varying fields of ground motion and non-uniform distribution of objects, of high ground-motion coinciding with susceptible structures or sensitive people. Furthermore, the distribution of seismic effects (perceptions, structural damage, ground 
failure, and so forth) is probably controlled by local levels of ground motion with extraordinarily high values, rather than some overall regional average level of ground motion. These questions clearly deserve further investigation.

\section{SUMMARY AND CONCLUSIONS}

The following statements summarize the major findings of this study:

1) Using seismic source theory and a model of high-frequency seismic shaking as "band-limited white noise," one may derive a theoretical expression between Arias intensity, stress drop and source radius, and the source distance (eq. 7).

2) This expression can then be converted into a magnitude-distance relationship (eq. 11),

$$
\log \left(I_{h}\right)=\mathbf{M}-2 \log (R)-3.99 \text {. }
$$

3) This theoretical magnitude-distance relation was tested empirically against strong-motion data from several, wellrecorded California earthquakes. The effect of anelastic absorption was found to be virtually negligible, compared to geometric spreading, for source distances of less than $150 \mathrm{~km}$. A statistically significant log-linear correlation was found between Arias intensity and moment-magnitude (fig. 4), verifying the theoretical prediction of eq. 11 , and suggesting that static stress-drops for California earthquakes are approximately constant (100 bars).

4) An analysis of the residuals from fitting the total set of strongmotion data with equation (11) show no consistent variation with either source distance or magnitude, and appear to be normally distributed. The standard deviation of the residuals is equal to 0.365 .

5) Differences in Arias intensity were examined for several pairs of strong-motion records, where one member of the pair was located on bedrock, the other on soft soils or thick alluvium. The Arias intensities were consistently higher for the records from sites on soft soil or thick alluvium, with increases of up to an order-of-magnitude over the sites on bedrock.

6) Directivity, the asymmetrical propagation of the seismic source, was also found to have a significant influence on the azimuthal distribution of Arias intensity, with variations of up to an orderof-magnitude above or below the value predicted by equation 11 . 
7) The magnitude-distance relationship for Arias intensity (eq. 11), together with historical data on landslides from historical earthquakes, may be used to estimate the threshold value of Arias intensity required to trigger disrupted landslides. This threshold value may then be used to estimate limiting distances to this type of landsliding from a postulated future earthquake.

8) Arias intensity $\left(I_{h}\right)$ and Modified Mercalli $\left(I_{m m}\right)$ intensity have a statistically significant correlation coefficient $(0.748$ for 161 d.f.s). . Because of the large scatter in the data, however, regressions of $\log \left(I_{h}\right)$ on MMI (eq. 14) and MMI on $\log \left(I_{h}\right)$ (eq.

15) produce non-commutative results,

and,

$$
\log \left(I_{h}\right)=0.527 I_{m m}-3.816
$$

$$
I_{m m}=1.063 \log \left(I_{h}\right)-6.686
$$

respectively. Both relationships are equally valid, but the actual association between MMI and Arias intensity is probably more complicated than a simple linear correlation can fully express.

\section{ACKNOWLEDGMENTS}

I thank D. K. Keefer, Tom Hanks, and William Joyner for their careful reviews and stimulating questions. I also thank D. J. Andrews, and Joseph Ziony for their reviews of previous versions. E. L. Harp calculated the Arias intensity values for the strong-motion records from the 1987 Whittier and 1989 Loma Prieta earthquakes. A special thanks to Randy Jibson and Kaye Shedlock for their relentless encouragement. 
REFERENCES CITED:

Ambraseys, N.N., 1974, Notes on engineering seismology, in Solnes, J., ed., Engineering Seismology and Earthquake Engineering [NATO Advanced Study Institute, Izmir, 1973]: Leiden, Noordhoff, p. 33-54.

Anderson, J.G., Bodin, P., Brune, J.N., Prince, J., Singh, S.K., Quaas, R., and Onate, M., 1986, Strong ground motion from the Michoacan, Mexico, earthquake: Science. v. 233, p. 1043-1049.

Arias, A., 1970, A measure of earthquake intensity, in Hansen, R., ed., Seismic design for nuclear power plants: Cambridge, Mass., Massachusetts Institute of Technology Press, p. 438-483.

Benioff, H., 1955, Mechanism and strain characteristics of the White Wolf fault as indicated by the aftershock. sequence, in Oakeshott, G.B., ed., Earthquakes in Kern County, California during 1955: California Division of Mines Bulletin 171, p. 199-202.

Bent, A.L., and Helmberger D.V., 1989, Source complexity of the October 1, 1987, Whittier Narrows earthquake: Journal of Geophysical Research, v. 94, p. 9548-9556.

Boatwright, J., and Boore, D.M., 1982, Analysis of the ground accelerations radiated by the 1980 Livermore Valley earthquakes for directivity and dynamic source characteristics: Bulletin of the Seismological Society of America, v. 72, p. 1843-1865.

Boore, D.M., 1983, Stochastic simulation of high-frequency ground motions based on seismological models of the radiated spectra: Bulletin of the Seismological Society of America, v. 73, p. 1865-1894.

Boore, D.M., Joyner, W.B., Oliver, A.A., and Page, R.A., 1978, Estimation of ground motion parameters: U.S. Geological Survey Circular 795, $43 \mathrm{p}$.

Borcherdt, R.D., 1970, Effect of local geology on ground motion near San Francisco Bay: Bulletin of the Seismological Society of America, v. 60, p. 29-61.

Borcherdt, R.D., Gibbs, J.F., and Lajoie, K.R., 1975, Maps showing maximum earthquake intensity predicted in the southern San Francisco Bay region, California, for large earthquakes on the San Andreas and Hayward faults: U.S. Geological Survey Map MF-709, 11 p., scale 1:125,000.

Borcherdt, R.D., and Gibbs, J.F., 1976, Effects of local geological conditions in the San Francisco Bay region on ground motions and the intensities of the 1906 earthquake: Bulletin of the Seismological Society of America, v. 66, p. 467-500. 
Bracewell, R., 1965, The Fourier transform and its applications: New York, McGraw-Hill, 381 p.

Brune, J.N., 1970, Tectonic stress and the spectra of seismic shear waves from earthquakes: Journal of Geophysical Research, v. 75, p. 49975009.

Brune, J. N., 1971, Correction, Journal of Geophysical Research, v. 76, p. 5002.

Darragh, R. B., and Shakal, A.F., 1991, The site response of two rock and soil station pairs to strong and weak ground motion: Bulletin of the Seismological Society of America, v. 81, p. 1885-1899.

Dobry, R., Idriss, I.M., and Ng, E., 1978, Duration characteristics of horizontal components of strong-motion earthquake records: Bulletin of the Seismological Society of America, v. 68, p. 1487-1520.

Espinosa, A.F., 1982, $\mathrm{M}_{\mathrm{L}}$ and $\mathrm{M}_{\mathrm{o}}$ determination from strong-motion accelerograms, and expected-intensity distribution, in The Imperial Valley, California Earthquake of October 15, 1979: U.S. Geological Survey Professional Paper 1254, p. 433-438.

Espinosa, A.F., Husid, R., and Quesada, A., 1976, Intensity distribution and source parameters from field observation, in Espinosa, A.F., ed., The Guatemalan earthquake of February 4, 1976, a preliminary report: U.S. Geological Survey Professional Paper 1002, p. 52-56.

Etheredge, E. and Porcella, R., 1987, Strong-motion data from the October 1, 1987, Whittier Narrows earthquake: U.S. Geological Survey OpenFile Report 87-616, 64 p.

Evernden, J.F., 1975, Seismic intensities, "size" of earthquakes, and related phenomena: Bulletin of the Seismological Society of America, v. 65, p. 1287-1315.

Evernden, J.F., Kohler, W.M., and Clow, G.D., 1981, Seismic intensities of earthquakes of conterminous United States--their prediction and interpretation: U.S. Geological Survey Professional Paper 1223, 56 p.

Gutenberg, B., 1957, Effects of ground on earthquake motion: Bulletin of the Seismological Society of America, v. 47, 221-250.

Gutenberg, B., and Richter, C.F., 1942, Earthquake magnitude, intensity, energy and acceleration: Bulletin of the Seismological Society of America, v. 32, 163-191. 
Hanks, T.C., 1979, b-values and $\omega^{-\gamma}$ seismic source models--implications for tectonic stress variations along active crustal fault zones and the estimation of high-frequency strong ground motion: Journal of Geophysical Research, v. 84, p. 2235-2242.

Hanks, T.C., 1982, $f_{\max }$ : Bulletin of the Seismological Society of America, v. 72 , p. $1867-1879$.

Hanks, T.C., and Kanamori, H., 1979, A moment magnitude scale: Journal of Geophysical Research, v. 84, p. 2348-2350.

Hanks, T.C. and McGuire, R.K., 1981, The character of high-frequency strong ground motion: Bulletin of the Seismological Society of America, v. 71, p. 2071-2095.

Hanks, T.C., and Boore, D.M., 1984, Moment-magnitude relations in theory and practice: Journal of Geophysical Research, v. 89, p. 6229-6235.

Hanks, T.C., and Johnston, A.C., 1992, Common features of the excitation and propagation of strong ground motion for North American earthquakes: Bulletin of the Seismological Society of America, v. 82, p. 1-23.

Housner, G.W., 1965, Intensity of earthquake ground shaking near the causative fault: Proceedings of the Third World Congress of Earthquake Engineering, New Zealand, 1965, (Session III), v. 1, p. 94-111.

Housner, G.W., 1971, General features of the San Fernando earthquake, in Jennings, P.C., ed., Engineering features of the San Fernando earthquake, February 9, 1971: Earthquake Engineering Research Lab. Report, EERL 71-02, Pasadena, Ca., California Institute of Technology, p. 1-57.

Joyner, W.B., Warrick, R.E., and Fumal, T.E., 1981, The effect of Quaternary alluvium on strong ground motion in the Coyote Lake, California earthquake of 1979: Bulletin of the Seismological Society of America, v. 71, p. 1333-1349.

Joyner, W.B., and Boore, D.M., 1981, Peak horizontal acceleration and velocity from strong-motion records including records from the 1979 Imperial Valley, California, earthquake: Bulletin of the Seismological Society of America, v. 71, p. 2011-2038.

Keefer, D.K., 1984, Landslides caused by earthquakes: Geological Society of America Bulletin, v. 95, p. 406-421. 
Leyendecker, E.V., Highland, L.M., Hopper, M., Arnold, E.P., Thenhaus, P., and Powers, P., 1988, The Whittier Narrows, California earthquake of October 1, 1987--early results of isoseismal studies and damage surveys: Earthquake Spectra, v. 4, p. 1-10.

McCann, M.W., 1981, RMS acceleration and duration of strong ground motion: Stanford University, John Blume Earthquake Engineering Center Technical Report No. 46.

Medvedev, S.V., 1962, Engineering Seismology: Moscow, Academia Nauk, Institute of Physics of the Earth [translated from Russian by the Israel Program for Scientific Translations, Jerusalem, 1965], 260 p.

Mendoza, M.J., and Prince, J., 1986, Preliminary report on the earthquake of September 19, 1985, and its effects on structures and foundations in Mexico City: Geotechnical News, March, 1986, p. 20-29.

Nason, R., 1982, Seismic-intensity studies in the Imperial Valley, in The Imperial Valley, California Earthquake of October 15, 1979: U.S. Geological Survey Professional Paper 1254, p. 259-264.

Nuttli, O.W., 1973, Seismic wave attenuation and magnitude relations for eastern North America: Journal of Geophysical Research, v. 78, p. 876-885.

Porcella, R.L., Matthiesen, R.B., and Maley, R.P., 1982, Strong-motion data recorded in the United States, in The Imperial Valley, California Earthquake of October 15, 1979: U.S. Geological Survey Professional Paper 1254, p. 289-318.

Reagor, B.G., Stover, C.W., Algermissen, S.T., Steinbrugge, K.V., Hubiak, P., Hopper, M.G., and Barnhard, L.M., 1982, Preliminary evaluation of the distribution of seismic intensities, in The Imperial Valley, California Earthquake of October 15, 1979: U.S. Geological Survey Professional Paper 1254, p. 251-258.

Richter, C.F., 1958, Elementary Seismology: San Francisco, W.H. Freeman, 768 p.

Schnabel, P.B., and Seed, H.B., 1973, Acceleration in rock for earthquakes in the Western United States: Bulletin of the Seismological Society of America, v. 63, p. 501-516.

Shakal, A.F., Huang, M.J., Ventura, C.E., Parke, D.L., Cao, T.Q., Sherburne, R.W., and Blazquez, R., 1987, CSIMP strong-motion records from the Whittier, California earthquake: California Division of Mines and Geology Report No. OSMS 87-05, 198 p. 
Trifunac, M.D., and Brady, A.G., 1975, On the correlation of seismic intensity scales with the peaks of recorded strong ground motion: Bulletin of the Seismological Society of America, v. 65, p. 139-162.

Vanmarcke, E.H., and Lai, S.-S.P., 1980, Strong-motion duration and rms amplitude of earthquake records: Bulletin of the Seismological Society of America, v. 70, p. 1293-1307.

Wilson, R.C., and Keefer, D.K., 1985, Predicting areal limits of earthquakeinduced landsliding, in Ziony, J.I., ed., Earthquake hazards in the Los Angeles metropolitan area: U.S. Geological Survey Professional Paper 1360, p. 317-345.

Wood, H.O., 1908, Distribution of apparent intensity in San Francisco, in The California Earthquake of April 18, 1906, Report of the State Earthquake Investigation Commission [Lawson, A.C., chairman]: Washington, D. C., Carnegie Institute of Washington Pub. 87, p. 220245.

Wood, H.O., and Neumann, F., 1931, Modified Mercalli Intensity scale of 1931: Bulletin of the Seismological Society of America, v. 21, p. 277283.

Wosser, T.D., Campi, D.E., Fovinci, M.A., and Smith, W.H., 1982, Damage to engineered structures in California, in The Imperial Valley, California Earthquake of October 15, 1979: U.S. Geological Survey Professional Paper 1254, p. 273-288. 